IZA DP No. 10084

\title{
Performance Pay and Malnutrition
}

Prakarsh Singh

Sandip Mitra

July 2016 


\title{
Performance Pay and Malnutrition
}

\author{
Prakarsh Singh \\ Amherst College \\ and IZA \\ Sandip Mitra \\ Indian Statistical Institute
}

\section{Discussion Paper No. 10084 \\ July 2016}

\author{
IZA \\ P.O. Box 7240 \\ 53072 Bonn \\ Germany \\ Phone: +49-228-3894-0 \\ Fax: +49-228-3894-180 \\ E-mail: iza@iza.org
}

Any opinions expressed here are those of the author(s) and not those of IZA. Research published in this series may include views on policy, but the institute itself takes no institutional policy positions. The IZA research network is committed to the IZA Guiding Principles of Research Integrity.

The Institute for the Study of Labor (IZA) in Bonn is a local and virtual international research center and a place of communication between science, politics and business. IZA is an independent nonprofit organization supported by Deutsche Post Foundation. The center is associated with the University of Bonn and offers a stimulating research environment through its international network, workshops and conferences, data service, project support, research visits and doctoral program. IZA engages in (i) original and internationally competitive research in all fields of labor economics, (ii) development of policy concepts, and (iii) dissemination of research results and concepts to the interested public.

IZA Discussion Papers often represent preliminary work and are circulated to encourage discussion. Citation of such a paper should account for its provisional character. A revised version may be available directly from the author. 


\section{ABSTRACT}

\section{Performance Pay and Malnutrition ${ }^{\star}$}

We carry out a randomized controlled experiment in West Bengal, India to test three separate performance pay treatments in the public health sector. Performance is judged on improvements in child malnutrition. We exogenously change wages of government employed child care workers through either absolute or relative incentives. We also test for the impact of high and low absolute incentives. Results show that high absolute incentives reduce severe malnutrition by 6.3 percentage points over three months. Result is consistent with a reported increase in protein-rich diet at home in the high absolute treatment. There are no significant effects on health outcomes of other incentive arms. Results remain robust to propensity score matching, reversion- to-mean and a placebo check.

JEL Classification: M52, I12, I38, J38

Keywords: performance pay, child malnutrition, absolute and relative incentives

Corresponding author:

Prakarsh Singh

Department of Economics

Amherst College

P.O. Box 2201

Amherst, MA 01002-5000

USA

E-mail: psingh@amherst.edu

\footnotetext{
* We acknowledge funding for this project by the Dean of the Faculty at Amherst College. We are grateful to Hongye Guo, Alvaro Morales, and Arup Ratan Poddar for excellent research assistance and Sonia Bhalotra, Jere Behrman, Jun Ishii, Chris Kingston, John Maluccio, Subha Mani and Geof Woglom for their comments. We also thank the mothers, workers and children who took part in this experiment and the enumerators who painstakingly carried out the interviews. Thanks also go to the Social Welfare Department at Maheshtala for their co-operation. Finally, we would like to thank the seminar and conference participants at University of Essex, RAND Corporation, UC Berkeley, UC Santa Cruz, USC, LAC-Dev (Colgate University), NEUDC (Harvard University), MIEDC (University of Minnesota), PAC-Dev (UCLA), Southern Economics Association conference (Atlanta) George Washington University, World Bank, Washington and Lee University, Boston University, Swarthmore College, Williams College, ISI New Delhi and ISI Kolkata. IRB Approval Protocol \# 12-151.
} 


\section{Introduction}

In developing countries, performance pay for providers is still in its infancy and there is scant evidence on how to optimally structure contracts on the supply-side (Hasnain, Manning and Pierskalla, 2012). In this study, we carry out one of the first randomized controlled experiments in a developing country to test for the impact of high and low performance-based incentives, where performance is judged on improvements in health outcomes.

There are 1.31 million child day care centers in India under the Integrated Child Development Services (ICDS), a government-sponsored program. ${ }^{1}$ Each center is staffed by a childcare worker who is responsible for supervising children between ages 3-6 years during day-time, providing them mid-day meals, teaching mothers about child nutrition, imparting non-formal pre-school education and facilitating health check-ups by doctors. ${ }^{2}$ The child caregiver is paid fixed wages by the government and their jobs are widely considered to be secure. The centers are widespread across India and admission is free. Quality of service delivery has often come under scrutiny (see for example, Chaudhury et al. (2006) and Das and Hammer (2005)). A recent household survey in 100 Indian districts reveals that 96 percent of the villages are served by these centers, although only 50 percent provide food on the day of survey and 19 percent of the mothers report that the center worker provides nutrition counselling (HUNGaMA report, 2011). Gragnolati et al. (2005) find that leakage of meals to nontargeted beneficiaries is widespread and childcare workers do not give guidance to parents on improving nutrition within the family food budget. Despite the ICDS program being in place since 1975, an estimated 1.27 million children die every year in India because they are malnourished. ${ }^{3}$

\footnotetext{
${ }^{1}$ Between 2007-2012, $\$ 7.4$ billion has been allocated by the central government to the Integrated Child Development Scheme (Lok Sabha, 2012).

${ }^{2}$ Centers also act as food distribution centers for pregnant women, adolescent girls and children under the age of three years.

${ }^{3}$ Malnutrition is known to be associated with increasing a child's susceptibility to dis-
} 
We carry out an experiment with the ICDS in West Bengal, India to test three separate performance pay treatments for childcare workers. Performance is judged on improvements in child malnutrition. In the first arm, the wages of these government-employed child caregivers are topped with a basic level of incentives conditional on improvement in child health outcomes. As the bonuses are determined by improvements in their own center's children, the incentives are also absolute. The second treatment introduces high absolute incentives in addition to the usual fixed wages paid by the government. These incentives are twice as high as compared to the first treatment for the same improvement in their center's children. Finally, we test for the impact of basic proportional relative performance pay on child health. Here, the bonuses change depending upon a worker's performance in improving health of her center's children relative to the performance of other workers in improving health of children in their centers. All treatments also include supplying all mothers with low-cost recipe books (each listing ten simple recipes) in line with complementarity between supply-side incentives and demand-side information (Singh, 2015). Comparing relative and absolute incentive schemes as well as changing the gradient of the incentive pay have never been studied before in the public health domain.

The key findings are as follows. High absolute incentives reduce severe malnutrition by about 6.3 percentage points over three months. We find evidence for behavioral change at home in response to better monitoring of mothers by incentivized caregivers. We observe that mothers exposed

ease (Behrman et al. 2004), and decreasing labor productivity in the future (Alderman and Behrman, 2006). Conversely, there are high economic returns to increasing birthweight (Behrman and Rosenzweig, 2004). The fraction of disease attributable to being underweight is $61 \%$ for diarrhea, $57 \%$ for malaria, $53 \%$ for pneumonia, $45 \%$ for measles, and $53 \%$ for other infectious diseases (Fishman et al., 2004). Relative risk of death from infection is twice as high for severely malnourished as for moderately malnourished children and nine times higher than normal weight children (Caulfield et al., 2004). Solutions based purely on improving individual diets through economic growth are of limited effectiveness, as Behrman and Deolalikar (1987) showed that nutrient elasticities with respect to income may be close to zero. 
to highly incentivized workers report a higher consumption of protein and calories (lentils and meat) by their children. There are no significant effects on child health of the basic absolute or basic relative incentives during this period. Despite this being a randomized experiment, we check for common trends prior to the randomization. We carry out a placebo check that illustrates similar trends across all groups. Results are also robust to several propensity score matching methods, reversion-to-the-mean and placing Lee bounds on the estimates to account for attrition.

This paper contributes to the empirical literature on the effects of incentive pay on performance in organizations. Providing incentives for improvement in only malnourished children may lead to the worker applying extra effort at the cost of children who are normal weight. The incentive treatments in the experiment were designed to disincentivize the worker for a decline in weight-for-age grade. Gaming of incentives was found in Vermeersch and Kremer (2005) and Sylvia et al. (2012). These concerns are addressed by hiring, training and monitoring independent enumerators.

In one of the first papers linking performance pay to health in a developing country, Basinga et al. (2011) and Gertler and Vermeersch (2012) report that bonuses based on inputs and services-based performance increased the delivery of health services by 23 percent in Rwanda, although, there were no improvements in the number of women completing all prenatal care visits or in children receiving full immunization schedules. As observed in Miller and Babiarz (2013), we find that performance incentives based on outcomes can help local providers use their knowledge productively even though the outcome is only partly under the control of the provider. On the other hand, health outcomes can often be costly to measure as compared to inputs and providers may lack knowledge and skills to work towards obtaining the performance bonus.

It is rare to find an exogenous change in compensation schemes or a valid control group (Prendergast, 1999; Chiappori and Salanie, 2003). This may 
be crucial if there are other management changes that are taking place at the same time or if unobservable factors can influence both outcome and compensation structure. There could also be feedback of performance on the type of compensation. There exists almost no research on exogenously changing incentive schemes for workers in a public health organization within a controlled experiment. Propper et al. (2010) find evidence from a natural experiment that performance pay in Britain's National Health Service met its goal of reducing waiting times without a deterioration in health services and patient health. ${ }^{4}$ Mullen et al. (2010) find no adverse impact on quality in a pay-for-performance program in California but higher bonuses led to better health outcomes.

There has been very little experimental research on performance incentives in health programs of low and middle-income developing countries (Miller and Babiarz, 2013). An exception in providing incentives on the demand-side is Banerjee, Kothari and Duflo (2010) who incentivize immunization coverage in rural Rajasthan for mothers and find large increases in uptake. Hasnain, Manning and Pierskalla (2012) compile the experimental evidence on performance pay in the public sector and conclude that it is extremely scarce, especially in developing countries. ${ }^{5}$ The two studies they cite in this sub-field are Basinga et al. (2011) in Rwanda and Singh (2015) in India. ${ }^{6}$ Miller et al. (2012) show that performance incentives provided to primary school principals for reducing anemia in China are effective in reducing anemia prevalence by $25 \%$ by the end of the academic year as the incentivized principals influenced parents to change the child's eating behavior at home. Individual providers help solve the principal-agent problem that

\footnotetext{
${ }^{4}$ In the private sector in the US, medical studies have shown positive effects of performance pay for nursing homes (Petersen et al., 2006; Norton, 1992).

${ }^{5}$ Control groups are often not comparable even in developed countries (Christianson et al., 2008).

${ }^{6}$ Singh (2015) provides evidence for the effectiveness of performance pay to government health workers and how performance pay along with demand-side information significantly reduces malnutrition in Chandigarh, India.
} 
may arise with organization-level incentives as they can use local information (unobservable to the researchers) to influence behavior on the demand-side. ${ }^{7}$

We delineate the conceptual framework in Section 2, the context in Section 3, and empirics in Section 4. Section 5,6 and 7 provide main results, robustness checks and mechanisms. Section 8 concludes.

\section{Conceptual Framework}

In the public sector, performance-based incentive schemes are rarely seen because of the following reasons. First, shocks to output may be salient reducing the efficacy of performance incentives. Second, output may be less easily observable. Third, output may not directly respond to an increase in effort (may depend on demand-side also). Fourth, workers may be differently motivated (Besley and Ghatak, 2005) and may exert more effort in response to non-financial awards as shown by Ashraf, Bandiera and Lee (2014) and Ashraf, Bandiera and Jack (2012). In our context, we test for the impact of financial incentives and have a measurable health outcome (weight-for-age). Moreover, scope for multi-tasking by these childcare workers is very limited as the level of inefficiency is already high as reported by several studies above.

In response to the financial incentives, the worker may now have a higher opportunity cost for not distributing food at her center according to guidelines and for not counselling mothers. Moreover, as incentives are promised for every malnourished child in her center, a worker will potentially receive a higher reward for the same increase in effort if her center has a higher pro-

\footnotetext{
${ }^{7}$ Latest research also focuses on social distance and interaction of incentives. Kingdon and Rawal (2010) show that a student's achievement in a subject in which the teacher shares the child's gender, caste and religion, is on average nearly a quarter of a standard deviation higher than the same child's achievement in a subject taught by a teacher who does not share the child's gender, caste or religion. Our results reveal that incentive pay interacts with improving health of boys more than girls even though all the caregivers are women. This may indicate an interaction of taste-based preferences with incentives for improving health, leading to implications about gender inequality even as public sector efficiency is enhanced.
} 
portion of children who are malnourished. We can check for a dose response for workers and this may support our findings if high-powered incentives are more effective than low-powered incentives. However, there could be crowding out of intrinsic motivation if incentives are too low (Gneezy and Rustichini, 2000). Thus, it is theoretically possible that low-powered incentives may be even less effective as compared to the control group. It is also possible that the low-powered incentives may be sufficient to improve health outcomes at the same rate as high-powered incentives. Finally, there may be selective targeting at the intensive margin. Workers may focus more on those closer to an upper threshold of weight-for-age and neglect those further down. To account for this possibility, we factor disincentives into the three schemes such that marginal improvements in malnutrition grade are rewarded and marginal falls penalized. Nevertheless, we check for selective targeting in our section on mechanisms.

The model in the Appendix theoretically motivates testing for the proportional relative performance pay scheme and predicts that it will be more cost effective for the policy maker to implement a basic level of relative performance pay as opposed to a basic level of absolute performance pay to obtain the highest effort from the worker. ${ }^{8}$ The intuition behind the model is as follows. Under risk neutrality, there is no difference between absolute and relative incentives for the policy maker to induce the same high effort for agents (Lazear and Rosen, 1981). Public sector employees have been shown to be more risk averse as compared to those in the private sector (Buurman et al., 2012). With risk aversion and common shocks, however, relative incentives can dominate absolute incentives (Green and Stokey, 1983). Relative pay filters the common shock making agents face lower risk as compared to

\footnotetext{
${ }^{8}$ One way to motivate the relative incentives scheme is to appeal to the "competitive" nature of agents. This could make workers who are more competitive relatively more efficient under a relative incentive as opposed to an abolute incentive contract and the reverse would hold for workers who are less competitive. In the model we assume away differences in competitiveness among individuals.
} 
absolute pay. Under the relative incentive scheme, workers' pay depends on the ratio of individual productivity to average productivity among all coworkers in a field. Another practical advantage is that of budget predictability under the relative scheme. We motivate the treatments by proving that the costs associated with the absolute scheme are always greater than the relative scheme when a common shock is possible and public sector agents are risk-averse.

\section{Context}

There are 1.31 million day care centers across India that offer child care and nutritional counseling services. These are run by the government under the umbrella of Integrated Child Development Services (ICDS) through the Social Welfare Department. Each center is usually staffed by one government worker and an assistant. Workers can affect health of the child through two primary channels: first, providing mid-day meals to children and second, advising mothers on a nutritious diet. We study child care workers employed by the West Bengal government in Maheshtala Municipality in 24 South Pariganas District. Maheshtala is located in the Kolkata Metropolitan Region and is one of the largest municipalities in West Bengal. The municipality is divided into 35 wards. According to the 2011 Indian census, the population of Maheshtala was 449,423. The sex ratio of Maheshtala city was 945 females per 1000 males. Average literacy rate of Maheshtala was 82.63 percent of which male and female literacy was 86.08 and 78.98 percent. Children constituted $9.67 \%$ of the total population of Maheshtala. As of December 2011, the percentage of malnourished children under 5 in West Bengal, in terms of weight-for-age, was $38.7 \%$, below the national figure of $42.5 \%$ (Rajya Sabha, 2011). We were able to carry out this study in Maheshtala as the Social Welfare Department was keen to implement an experiment to tackle malnu-

trition. Here, the worker in a day care center has a fixed monthly salary of 
Rs. 4350 in Kolkata, which increases to Rs. 4413 after 10 years of service. All workers in this Municipality have similar tasks and operate under the ICDS scheme. Education, knowledge and experience of worker along with quality of infrastructure in the centers are controlled for in regressions below.

\subsection{Treatment}

There were three treatments that were implemented in the research project. All three treatments entailed free distribution of recipe books to all mothers apart from performance pay to workers. This was done because the combined treatment of incentives and information in Singh (2015) had been shown to increase weight in children and only incentives to workers or only recipes to mothers were individually ineffective. The recipe book is described later in the section.

To understand the performance pay treatments, consider the weight-forage categories established by WHO (2007). A child is classified as malnourished if she is more than two standard deviations away from the WHO standardized weight-for-age sex-specific mean and normal if she is less than two standard deviations away. She is moderately malnourished if she is more than two standard deviations but less than three standard deviations from the weight-for-age mean and severely malnourished if she is more than 3 standard deviations away from the weight-for-age mean. The Anganwadi workers are aware of these standards as they are required to maintain weight-for-age growth charts for each child.

The first treatment, titled Basic Absolute (BA) entailed a reward of Rs. 100 per child if the child's malnutrition grade improved from severe to moderate or moderate to normal and a corresponding Rs. 100 deduction from the total for a drop in grade from normal to moderate or moderate to severe. In other words, if:

$\mathrm{N}$ for each worker $=$ \# children who jump at least one grade - \# children 
who drop at least one grade

The total payment promised for each worker was Rs. $100 * \mathrm{~N}$ after three months. ${ }^{9}$ The per child bonus translated to about $2.25 \%$ of the monthly salary. As 33 percent of a center's children on were malnourished at baseline, a class of 30 children should have 10 malnourished children on average. Thus, a maximum incentive of $20.25 \%$ of the monthly salary could be expected for the average center (but payable after three months).

From the earlier experiment, it was not clear how the slope of performance pay was related to effort. In the second treatment, called High Absolute (HA treatment), the payout promised to the workers after three months was Rs. $200 * \mathrm{~N}$, where $\mathrm{N}$ was defined in the same way. However, if more children suffered declines as opposed to improvements, the workers were not asked to make payments. For example, if the number of children who jump from severe to moderate $=4$ and the number of children who drop from normal to moderate $=2$, the total payment would be Rs. $(4-2) * 100=$ Rs. 200 in the BA treatment and (4-2) * $200=$ Rs. 400 in the HA treatment. This treatment translates to a per child bonus of about $4.5 \%$ of the monthly salary.

As all the schemes were implemented in the presence of senior staff and under the signed approval of the local Director of Social Welfare Department, the promises could be seen as credible commitments to the workers. The average payout in Chandigarh for the basic absolute incentive with recipe book had been Rs. 291 per worker but the monthly worker salary was Rs. 2000 per month in 2010 (Singh, 2013). Since the workers' salary was almost twice in Maheshtala as compared to Chandigarh, the high absolute treatment can also be considered a test of the previous experiment's treatment if the slope is considered to be a proportion of the salary. Thus, the first two treatments can also throw light on the relative effectiveness of a constant slope of Rs. 100 versus the same slope as a proportion of total income.

\footnotetext{
${ }^{9}$ Approximately, 1 US\$ = Rs. 60 in July, 2013.
} 
The third treatment, or the basic relative (BR treatment), was allocated a pot of money containing on average Rs. 291 per worker to keep it consistent with the ex-ante expected payout in the basic absolute treatment.

$\mathrm{T}$ for each worker $=$ sum of all positive $\mathrm{N}$ in that treatment group

$$
\text { Payout }=55 \text { workers } * 291 *(\mathrm{~N} / \mathrm{T})=16000(\mathrm{~N} / \mathrm{T})
$$

The total amount for 55 workers would be approximately Rs. 16000 . However, the payout to each worker would depend upon her performance relative to others in the group. For example, if the worker's $\mathrm{N}=10$ and the sum of all positive $\mathrm{N}=100$ in her treatment group of 55 workers, the worker would get 10 percent of the total amount $=$ Rs. 1600. If each worker performs equally, they each get approximately Rs. 300 in the basic relative treatment. The relative treatment is also similar to Bandiera et al. (2004), where the workers' pay depended on the ratio of individual productivity to average productivity among all co-workers in a field. None of the schemes could reduce workers' income, and all were accompanied by information provided directly to mothers.

Workers in each treatment group participated in three separate workshops at the end of the baseline round (one for each treatment), where they were handed goal cards. The goal cards listed target weight for each child in their center after three months. Goal was the threshold for achieving moderate malnutrition status for the presently severely malnourished child (after accounting for the increase in age at endline) and achieving normal malnutrition status if the child is currently moderately malnourished. If the child was currently in the normal range, a maximum threshold was provided below which the child would become malnourished and penalty imposed. The workers were told about their respective treatments with the help of illustrative examples and all doubts were clarified.

The recipe book that was distributed in all treatments had ten economical and nutritious recipes for 3-6 year old children. These were government 
approved recipes and the recipes were chosen with the help of the Food and Nutrition Board, Kolkata. Each recipe could be made within a budget of Rs. 5 at home, contained local ingredients and listed the step-by-step method of preparation and nutritive values per 100 gms. The individual nutritive values were of calories, protein, iron and carotene. The book was translated and printed in Bengali, the local language. Some of the recipes were as follows: Puffed Rice Bengal Gram Mix, Rice Food Mix, Suji Porridge, Dalia Porridge, Chidwa Pulao and Chidwa Laddoo. These were rich in protein and calories to counter child malnutrition. Most used either lentils for increasing protein and rice, wheat or jaggery for increasing calorie count.

\subsection{Methodology}

We obtained preliminary data from the Social Welfare Department, Government of West Bengal on the number of registered students and average malnutrition in each center, manual randomization at the cluster level was conducted at the Department by a lottery. Each cluster consists of several centers. All centers with fewer than 20 registered students were dropped from the sample at this initial stage to improve power. In total, 34 clusters were selected for the study covering 209 centers. ${ }^{10}$ The senior department officials (supervisors) asked to be involved in the selection procedure, so they were invited to participate in the lottery.

Four empty boxes were placed in the Department's head office, each corresponding to an undisclosed treatment or control group in the presence of a research assistant and supervisors. Thirty four slips were labeled with their cluster number and the total number of centers in that cluster. These slips were then folded and shuffled by an assistant such that the information on the slips was not visible. A supervisor was asked to select a folded slip and place inside the first box. Thereafter, a second supervisor placed a folded

\footnotetext{
${ }^{10}$ Out of 35 clusters in the Municipality, only one cluster did not have any centers with 20 or more students registered at the time.
} 
slip into the second box. After one slip had been placed in each of the four boxes by supervisors, the assistant would then read off the number of centers allocated to each box at the end of each round. When the total number of centers accumulated for a box exceeded 50, the assistant was aked to shut the box. This was done to have at least 50 centers in each group for adequate sample size according to power calculations. Thus, treatments were assigned exogenously through cluster randomization contemporaneously along with a pure control group. All centers were based entirely within one geographic block and there was no endogenous selection into the treatment. Table 1 shows the total clusters and centers allocated to each group and Figure 1 plots the assignment on a map provided by the Department.

$<$ Table 1 and Figure 1 about here $>$

The baseline was carried out during March-May, 2012 and the endline three months later between August-September, 2012. A window of three months was chosen for the experiment because it is the average time between two medical check-ups by the local Health Department. The duration was verified to be sufficient for a grade improvement to occur by doctors at the local office of the Health Department, Government of India and was comparable to the earlier experiment. At baseline and endline, a team of enumerators (supervised by an assistant and project manager) weighed all children present in the center on a digital weighing machine, interviewed their mothers and the center workers. The recipe books were distributed to all the mothers (except in the control group) after their interviews were taken at the centers. Previous weights of children (on average two months prior to baseline) were also recorded at baseline from the weight record registers of the workers. 


\section{Empirics}

\subsection{Empirical specification}

The main regression specification for finding the average effect of the treatments on weight of a child is as follows:

$$
\begin{aligned}
w_{i j t}= & \alpha(\text { post })_{t}+\beta(B A)_{j}+\gamma(H A)_{j}+\rho(B R)_{j}+\eta(\text { post } * B A)_{j t}+ \\
& \theta(\text { post } * H A)_{j t}+\omega(\text { post } * B R)_{j t}+X_{i j t}+\varepsilon_{i j t}
\end{aligned}
$$

$w_{i j t}$ is the weight of a child $i$ in cluster $j$ at time $t$. The variable post is a dummy that is 0 for baseline and 1 for endline. The variables $B A, H A$ and $B R$ are 1 if the child is in the treatment basic absolute, high absolute or basic relative respectively and 0 otherwise. The omitted category is the control group. $X_{i j t}$ are individual and center specific controls specified in the following section. The error term is clustered at the cluster level. The variable post accounts for the natural increase in weight in from baseline to endline, all seasonal effects on weight, regional shocks to food prices and any management changes or unobservables that would impact all groups in the same way. $\beta, \gamma$ and $\rho$ are the baseline differences between the individual treatments and the control. $\eta, \theta$ and $\omega$ give us the difference-in-differences estimates for the effect of each of the three treatments. This interpretation rests on the identification assumption that there are no time varying and group-specific effects that are correlated with the treatments (common trend assumption). We should not expect there to be common trends amongst the groups as the clusters were randomly assigned into one of the four groups. We cluster standard errors at the level of a slum cluster, which was the unit of randomization.

Although usually it is not required to check this assumption with ran- 
domization, we carry out a placebo check to corroborate that pre-trends are similar across all groups. For the placebo check, we define post $=1$ for baseline and 0 for the weight recorded in registers prior to baseline (on average about two months before). Running the above regression with this new definition should allow us to test if there are changes in the difference-in-difference estimates from what we had obtained earlier. We should not observe any significant difference-in-difference estimates with the placebo regression for common pre-trends assumption to hold.

\subsection{Summary statistics and attrition}

The summary statistics at baseline in Table 2 reveal that mother's age is on average 27 years and is similar across the four groups. ${ }^{11} 73 \%$ of the mothers in the control group can read and this is also similar across groups, which is comparable to the 2011 Indian Census finding of 78\% literacy for women in Maheshtala. The normalized differences show that differences between groups are not significant as long as the normalized difference is less than 0.25 (Imbens and Rubin, 2007). The weights and ages of children (around 13.5 kilograms and 4.2 years) as well as the malnutrition status are similar across all groups. The malnutrition rate is $33 \%$ at baseline with close to $9 \%$ being severely malnourished and the rest being moderately malnourished. The monthly income of a household was approximately $\$ 70$ for four members (two adults and two children), showing that families on average live below the poverty line in this sample. This is also statistically insignificant between the groups with HA group being the most similar to the control group along all variables. Ownership of mobile phones is high and water filters is low. The least similar group, overall, is the BA group where mobile phone ownership and presence of water tap at home is significantly higher than the control. Anganwadi infrastructure as measured by presence of access to drinking water in the center or toilet in the center are also similar with close to $40 \%$ having

\footnotetext{
${ }^{11}$ Mother's age was around 28 years for the experiment in Chandigarh (Singh, 2015).
} 
a toilet and three quarters having drinking water. Thus, on average the variables appear to be well matched across groups with the HA group being the most similar to the control, followed by the BR group and then the BA group. In our difference-in-differences regression, health outcomes at baseline are insignificantly different across all treatments and control on average. We also control for all observables that may be different across groups in our conservative specification. Finally, robustness checks, such as propensity score matching and placebo check address any concerns about an unbalanced sample or differential pre-trends.

We might be worried about selective weighing of children in these groups despite checking by an independent supervisor and enumerator. Table 3 shows attrition rates. These are around $26 \%$ and similar across the four groups. Attrition rates tend to be higher in these centers as most students use the centers as a temporary pre-school before they gain admission to a government school. This is because the pre-school educational quality is poor with no official syllabus or exams. As many of the fathers are daily wage laborers who are prone to migrating where a higher wage is offered, their family also keeps moving with them. Attrition is not different by the main outcome variables depending upon treatment. This is illustrated by Appendix Table A2 where all coefficients of the variable interacting treatments with main outcome variables (weight, malnourished, grade, severe malnourished) are insignificant. Stand-alone coefficients on health outcomes and individual treatments are also insignificant (not shown).

\section{Main results}

The regression results from specification (1) are reported in Table 4 for a panel of children who were weighed twice during the study. The outcome variables in the first four columns are weight (in kilograms), dummy for mal-

nourished status, weight-for-age grade (ordered 0 to 2 from normal to severely 
malnourished) according to the WHO, and dummy for severely malnourished status. Standard errors are clustered at the level of a slum cluster, the unit of randomization.

The results reveal that the weight increase in the control group over three months was on average 283 grams and significant (similar to Chandigarh). This appears to be a "normal" increase in weight for the mix of malnourished and normal weight children over the time interval of three months. Notice, that the malnutrition levels remain similar in the control group over time, so simply taking part in the project does not lead to a reduction in malnutrition. The baseline levels of weight and other measures are similar in the four groups. There appears to be no significant impact of the basic absolute (BA) and basic relative (BR) treatments. However, BR appears to do much better than BA on average in improving weight but the estimate (225 grams in column (5)) is insignificant. As our model predicted, BR appears to be more cost effective than BA on average but the differences in impacts between the two are not significant to make a definitive conclusion.

The high absolute treatment shows a significant effect of an increase of 191 grams over and above the 283 grams in the control group from column (1). If we include controls, our estimate increases to 253 grams on top of 271 grams. Although malnutrition decrease is not significant at the $10 \%$ level, there appears to be a 4.6 percentage points reduction just under the $10 \%$ significance level. Ordered grades decrease (as 0 is normal) on average in the HA treatment. The weight increase is driven by the movement towards moderate status of severely malnourished children as can be shown by column (4). ${ }^{12}$ Severe malnutrition declines by almost 5 percentage points and is significant at the $5 \%$ level. The next four columns have the same dependent variables but also include control variables. The control variables used in columns (5)-(8) are pre-intervention household demographics (age of child, gender of child, to-

\footnotetext{
${ }^{12}$ In a different setting (Chandigarh), malnutrition had declined by 4.2 percentage points over three months in response to the absolute incentives and information to mothers providing some external validity.
} 
tal number of siblings), household assets (monthly income, food expenditure, number of rooms, proportion of goods owned in the kitchen, proportion of non-kitchen goods), parent-specific controls (mother's age, mother's religion, whether the mother is a housewife, literacy of mother and father, whether the mother scored a high or low quiz score), worker-specific controls (whether the worker is experienced or not, whether the worker is highly educated or not, whether the worker scored a high or low quiz score), and center-specific controls (dummy variables for the center's facilities: electricity, fan, helper, chart, blackboard, drinking water, and toilet). The preceding result on severe malnutrition is now more significant and the decline in severe malnutrition is now estimated to be 6.3 percentage points for HA treatment. ${ }^{13}$ This is a big decrease given the time period and may be able to sustain itself after three months because of immunity and resistance acquired by moderately malnourished children. Long-term positive effects were observed in Singh (2015) after discontinuation of a similar incentive scheme. Next, we consider the placebo results wherein we look for differences in the rates of growth in children between the groups pre-treatment. This is shown in Table A1 in the Appendix. We observe that even on average two months prior to treatment, the weight increase was not different across the different treatment and control groups and they were on same trajectories. There may be measurement error here as the weights were recorded by the center workers in their registers but there is no reason to expect a systematic upward or downward bias in any of the treatment groups. Figure 2 shows the differential trend in the high absolute treatment immediately after the treatment (located at two months) in comparison to the control group. The pre-baseline and baseline values are very similar in the high absolute and control groups. It is interesting to note that basic relative treatment appears to do better than the basic absolute treatment in the graph but the difference is not statistically

\footnotetext{
${ }^{13}$ The results are robust to including an intermediate set of controls. For details, see Table A4 in the Appendix.
} 
significant and neither is the difference at baseline between these groups and the control group significant.

$<$ Table 4 and Figure 2 about here $>$

As high absolute treatment seems to be effective in improving weights of children, we can conclude that slope of the incentive treatment as a proportion of salary matters in this context. In Table A3, we reproduce the main regression using Moulton clustering correction (as opposed to the standard clustering) as suggested by Angrist and Pischke (2008) in situations where the

main regressors (treatments) are fixed within a cluster and heteroskedasticity is not a huge problem. While all the coefficients stay the same, the standard errors increase across the board, as expected, leading to a few changes in the degree of significance of some coefficients. Thus, the coefficient Post*HA becomes insignificant in the weight regression, but it is still significant at $5 \%$ and $10 \%$ in the grade and severely malnourished regressions, respectively.

\section{Robustness checks}

The main result of the paper is that the high absolute incentive works to reduce severe malnutrition. We subject this result to three additional robustness checks: propensity score matching, controlling for reversion to the mean, and providing Lee (2009) bounds on our main result after accounting for attrition.

\subsection{Propensity Score Matching}

We carry out propensity score matching to account for differences in observables across the high absolute treatment and control groups that may be driving our result. It also helps us restrict our analysis to a counterfactual sample in the control group that looks more similar to the high absolute 
treatment sample at baseline. The validity of the RCT estimates is not only based on the common trends assumption as tested in the placebo check (Table A1) but also on adequately controlling for average group differences in health outcomes at baseline. Propensity score matching is a robustness check on the latter.

Propensity score is defined as the probability that a unit in the full sample receives the treatment, given a set of observed variables at baseline. We model the probability of being in the combined treatment as a function of all pre-treatment variables using the control group and high absolute treatment observations. These variables are the usual control variables used in the main results table. Next, we test for the robustness of our difference-in-differences estimates using three types of commonly employed propensity score matching techniques: nearest neighbor, radius, and kernel. Panels $\mathrm{A}, \mathrm{B}$ and $\mathrm{C}$ in Table 5 illustrate how the average change in weight in the combined treatment group varies relative to the control group under these methodologies. Moreover, the first row in each panel shows the average change in weight for the unmatched sample in the two groups and the second row displays the treatment effect on treated with the matched sample. The results for the unmatched and matched samples reveal similar estimates, suggesting that the control group is a valid counterfactual. The results indicate that the additional change in weight in the high absolute treatment is between 170 and 180 grams and this is significantly different from the change in the control group.

\subsection{Reversion to the mean}

It is possible that on average we get a significant effect on improving weight for the high absolute treatment but this may simply be a reversion-to-themean effect if the lighter children in that group showed faster catch-up (even though average weights were similar across groups at baseline). The placebo check above makes this possibility less likely but we propose another robust- 
ness check running a regression in wide form as follows:

$$
w_{i j 1}=\alpha w_{i j 0}+\beta(B A)_{j}+\gamma(H A)_{j}+\rho(B R)_{j}+X_{i j t}+\varepsilon_{i j t}
$$

By controlling for baseline weights of children as an independent variable, we allow the regression to determine the natural catch-up rate as opposed to imposing $\alpha=1$, as in the difference-in-differences specification. The results in Table 6 show that the significance of the main result survives this conservative check, making the main result more credible.

\subsection{Lee bounds}

We present bounds for samples with non-random selection as proposed by Lee (2009) in Table 7. The lower and upper bound correspond to extreme assumptions about the missing information that are consistent with the observed data (Tauchmann, 2012). These suggest a causal impact on the weight of the high absolute treatment should range between 157 grams and 204 grams in the worst and best case scenarios.

\section{Mechanisms}

One of the channels through which the weight may have increased may have been food at home. We test if mothers report changes in diet at home as this would lend more credence to the change in outcomes. In Table 8, we explore the demand-side channel of mother-reported diet given to child. The dietary variables considered here are lentils or pulses, fish, meat, green vegetables and sweets or desserts. Note that baseline levels of consumption are similar across all groups. Lentils or pulses intake (at least twice a week) shows a significant increase in consumption and so does meat. Lentil intake is consistent with mothers being asked to prepare recipes by the HA treatment workers. Recall that several recipes (six out of ten) contained lentils as their main ingredient. 
This is rich in protein and would help lower protein deficiency. There is no change in other types of dietary intakes for the HA group mothers. The mothers in the BA and BR group show no change in their reported food provision, which is again consistent with their results on weight change in Table 4.

Next, we explore heterogeneous effects of the treatments by age and gender of child. In Table 9, we run a triple difference regression to check for significant differences in average treatment effects for boys and girls. Surprisingly, we find that boys show a much greater increase in the high absolute treatment relative to girls (345 grams higher and this is significant at the $10 \%$ level). There may be an underlying gender bias that becomes more salient with the introduction of high absolute incentives. It may also be that boys have greater appetite or ask for more food in the centers and thus are able to get more food from the incentivized worker. Workers may expect that boys will show more weight gain in response to food in the center or that mothers will be less likely to cut down on food for boys leading to complementarity. However, this expectation may be incorrect, as we do not observe differential food intakes reported at home for boys and girls suggesting that gender bias is getting triggered at the center and not at home.

We also disaggregate our results on weight-for-age z-scores of children by age and gender in Table 10. The mean z-score in the sampled population at baseline is -1.43 . This means that the average child is 1.43 standard deviations away from the WHO (2007) standard for the child's age. We find that the high absolute treatment appears to drive greater changes in weights for children between the ages of 4 and 5 years. We also observe a significant increase for boys and a negligible and insignificant effect for girls and this is consistent with the estimates shown in Table 9.

Finally, we check for selective targeting of children who are close to the target threshold that may occur at the expense of those who are further away. The variable 'closetotarget' is defined to be 1 if the child is malnourished at 
baseline and her deficit weight (difference between the target weight and the actual weight) is less than the mean deficit weight and 0 otherwise. Target weight is defined as the threshold at which the child will improve her grade (i.e. would go from severely malnourished to moderately malnourished or from moderately malnourished to not malnourished). If there was selective targeting of those children in the incentive treatments who are close to the target threshold, the disincentive for a drop in grade may not have been as effective as anticipated. However, in Table 11, we observe that children close to the threshold do not appear to be selectively targeted in any of the treatments. Children who are closer to the target weight do not increase their weight at a statistically different pace than the ones who are further away from their target, which provides evidence against gaming of positive incentives. This seems to reiterate the importance of having disincentives for worse outcomes along with incentives for better outcomes. ${ }^{14}$

Do incentivized workers who have a greater proportion of malnourished children in their class show greater gains in weight for their children? This can be tested via a triple differences "dose response" regression as shown in Table 12. Indeed, we do observe a dose response for workers in the high absolute treatment implying greater rewards for centers who have a higher proportion of malnourished children at baseline. This may be because workers exert more effort when they know that they can get an even higher bonus if targets for malnourished children are achieved. However, it may also be driven mechanically because children who are more malnourished may show more gains at lower margin for the same inputs.

\footnotetext{
${ }^{14}$ One may also be concerned about kids being given water by workers before the measurement of weights at endline. However, 'center has access to drinking water' is one of the controls used in the main regression, and this access is associated with an insignificant and negative increase in weight on average.
} 


\section{Policy implications and Conclusion}

This paper is one of the first pieces of evidence in public health focusing on the elasticity of outcomes with respect to gradient of performance pay and also comparing absolute with relative treatments. We carry out a randomized controlled experiment to test three performance pay schemes in the government run childcare sector in India. First, we exogenously change wages of government employed child care workers to a component with basic absolute incentives to lower child malnutrition. The second treatment introduces high absolute incentives. Finally, we also test for the impact of basic relative incentives on child health. All treatments also include supplying mothers with recipe books. Overall, the results suggest that high absolute incentive works to reduce severe malnutrition by about 6.3 percentage points with controls and 4.9 percentage points without controls over three months. 31 out of 53 workers won a positive payout in the high absolute scheme. The average payout in the HA treatment was equivalent to an increase of 3.9 percent in monthly wages. This treatment arm also successfully replicates the combined treatment implemented in 2010 in Chandigarh, where the piece rate was set at the 'basic' level but the wages of child caregivers were almost half of the workers in West Bengal (Singh, 2015). A policy implication is that financial incentives will need to be re-calibrated as public sector wages increase in a growing economy.

Iron supplementation and deworming drugs have been amongst the most effective in reducing malnutrition. Bobonis et al. (2006) find that an increase in weight of $0.5 \mathrm{~kg}$ in five months for 2-6 year old slum children in Delhi due to iron supplementation and deworming. This led to increased participation rates and (estimated) higher wages provided a net benefit of $\$ 29$ per child for a cost of $\$ 1.70$ per child per year. In the HA treatment, the average weight gain per month is $84 \mathrm{gms}$ as opposed to $100 \mathrm{gms}$ per month in the iron and deworming treatment. Assuming a linear relationship between participation rates and change in weight over this range, the combined treatment should 
result in a net benefit of $\$ 24$ per child. Moreover, the explicit cost of the wages is $\$ 1.88$ per child per year, where $\$ 1.42$ is from the fixed wages to the workers, $\$ 0.16$ per child is from a one-time incentive payout to the workers and $\$ 0.30$ from recipe book printing and distribution. ${ }^{15}$ The estimated net benefit-cost ratio for the HA treatment turns out to be 12.8 .

This is on top of the reductions in child mortality that may arise due to a decrease in severe malnutrition. As the government expands access to centers across the country, results from this paper suggest that worker pay should not remain fixed even though the gains may be distributed unequally. Compensation needs to have a component of performance pay that increases as the fixed income goes up. The component should be based on weight-forage grade that is easily observable and well understood. Additionally, the worker should not have perverse incentives to reduce weights of children who are not malnourished.

A possible channel that may be generating this high incentive effect on weight include using recipe books to remind mothers to increase protein intake at home. Second, a change in food distribution at the center by the worker. Although it is difficult to isolate these channels as food distribution at center is not measured, large increases in weight are observed for boys as opposed to girls, for 4 to 5 year old children, and especially for those classes that had a higher proportion of malnourished children. This suggests that designing performance incentive schemes may create inequities in wages of workers depending on the demographic, gender and health profile of the class at baseline. In the future, we would also like to test the high relative

\footnotetext{
${ }^{15}$ The cost for our treatment is much lower than the World Bank (2006) figures for a nutrition education program of $\$ 2.50$ per person per year. It would be difficult to imagine the gains in weight to continue increasing linearly if the existing incentive scheme is applied quarterly due to at least four reasons. First, there are likely to be mechanical diminishing returns due to fewer remaining malnourished children in the Anganwadi. Second, participation rates (and thereby wages) are unlikely to increase as a child becomes normal weight. Third, there may be biological diminishing returns as the body adapts to increased calorie intake. Finally, workers may need to be motivated with higher incentives if their intrinsic motivation keeps getting crowded out.
} 
treatment which we were unable to test here due to availability of limited number of clusters and sample size. There could also be research on changing the slope of performance incentives along an observable dimension like gender to target both inefficiency and gender inequality.

The funds released for ICDS by the central government totalled $\$ 193.6$ million in 2011-2012 for West Bengal. If the state-allocated funds are included, this figure goes up to $\$ 221.5$ million. A large proportion of these funds goes towards fixed wages of child care workers. Yet, little is known about the most effective way of organizing labor contracts in this important area of public sector service. Through field experiments with the government, we can have a better handle at understanding what nudges work to motivate child care workers and reduce malnutrition rates, which have remained stagnant in India despite economic growth. Even without external validity, this has potentially life-saving implications on a large scale. Nevertheless, different settings within India can pose very different challenges, but one advantage of working within the same public organization can be easier replicability. We hope that further experimentation in this area can inform policy-makers on how to make public health service delivery more efficient. 


\section{References}

[1] Alderman, Harold and Jere R. Behrman. (2006) Reducing the Incidence of Low Birth Weight in Low-Income Countries Has Substantial Economic Benefits, World Bank Research Observer, World Bank Group, vol. 21(1), pages 25-48.

[2] Angrist, J. D. \& J. S. Pischke (2008). Mostly harmless econometrics: An empiricist's companion. Princeton University Press.

[3] Ashraf, N., O. Bandiera, and S. Lee (2014). Awards unbundled: Evidence from a natural experiment. Journal of Economic Behavior $\&$ Organization, Volume 100, April, Pages 44-63.

[4] Ashraf, N., O. Bandiera, and K. Jack (2012) No Margin, no Mission? A Field Experiment on Incentives for Pro-Social Tasks, CEPR Discussion Paper No. 8834.

[5] Bandiera, O., I. Barankay, and I. Rasul (2004) Relative and Absolute Incentives: Evidence on Worker Productivity, CEPR Discussion Paper No. 4431.

[6] Banerjee, A., D. Kothari, and E. Duflo (2010) Improving Immunisation Coverage in Rural India: Clustered Randomised Controlled Evaluation of Immunisation Campaigns with and without Incentives, BMJ, 340, c2220.

[7] Basinga, P., P. Gertler, A. Binagwaho, A. Soucat, J. Sturdy, and C. Vermeersch (2011) Effect on maternal and child health services in Rwanda of payment to primary health-care providers for performance: an impact evaluation, Lancet, 377(9775), 1421 - 1428.

[8] Behrman, Jere R., Susan W. Parker, Petra E. Todd, Kenneth I. Wolpin (2012) Aligning Learning Incentives of Students and Teachers: Results 
from a Social Experiment in Mexican High Schools, PIER Working Paper Archive 13-004, Penn Institute for Economic Research, Department of Economics, University of Pennsylvania.

[9] Behrman, Jere R. and Anil B. Deolalikar (1987) Will Developing Country Nutrition Improve with Income? A Case Study for Rural South India, Journal of Political Economy, University of Chicago Press, vol. 95(3), pages 492-507, June.

[10] Behrman, Jere R., S.W. Parker, P.E. Todd (2004) Long-Term Impacts of the Oportunidades Conditional Cash Transfer Program on Rural Youth in Mexico. Ibero America Institute for Economic Research, Discussion Paper No. 122.

[11] Behrman, J.R., M.R. Rosenzweig (2004) Returns to Birthweight. The Review of Economics and Statistics 86, 586-601.

[12] Besley, T. and M. Ghatak (2005) Competition and incentives with motivated agents. American Economic Review, 95, 616-636.

[13] Bobonis, G. J., E. Miguel, C.P. Sharma (2006) Anemia and school participation. Journal of Human Resources 41, Issue 4, 692-721.

[14] Buurman, M., J. Delfgaauw, R. Dur, S. Van den Bossche (2012) Public sector employees: Risk averse and altruistic?, Journal of Economic Behavior \&3 Organization, 83(3), 279-291.

[15] Caulfield, L.E., Richard, S.A., Black, R.E., 2004. Undernutrition as an underlying cause of malaria morbidity and mortality in children less than five years old. American Journal of Tropical Medicine and Hygiene 71, 55-63.

[16] Chaudhury, N., J. Hammer, M. Kremer, K. Muralidharan, and F. Rogers (2006) Missing in Action: Teacher and Health Worker Absence in Developing Countries. The Journal of Economic Perspectives, 20(1), 91-116. 
[17] Chiappori, P.A., Salanie, B. (2003) Testing Contract Theory: A Survey of Some Recent Work in Advances in Economics and Econometrics. Mathias Dewatripont, Lars P. Hansen, and Stephen J. Turnovsky, eds.. Cambridge University Press, Cambridge, UK.

[18] Christianson, J., S. Leatherman, and K. Sutherland (2008) Lessons From Evaluations of Purchaser Pay-for-Performance Programs-A Review of the Evidence, Medical Care Research and Review, 65(6), 5S-35S.

[19] Census of India (2011) Office of the Registrar General \& Census Commissioner, India (ORGI).

[20] Das, J. and J. Hammer (2005) Which doctor? Combining vignettes and item response to measure clinical competence, Journal of Development Economics, Elsevier, vol. 78(2), pages 348-383, December.

[21] Doyle, J., J. Graves, J. Gruber, S. Kleiner (2014) Measuring Returns to Hospital Care: Evidence from Ambulance Referral Patterns, Journal of Political Economy, forthcoming.

[22] Fishman, S., Caulfield, L.E., de Onis, M., Blossner, M., Mullany, L., Black, R.E. (2004) Malnutrition and the global burden of disease: underweight in Comparative quantification of health risks: the global and regional burden of disease due to 25 selected major risk factors. World Health Organization, Harvard University Press, Cambridge, MA.

[23] Gertler, P. and C. Vermeersch (2012) Using Performance Incentives to Improve Health Outcomes (June 1, 2012). World Bank Policy Research Working Paper No. 6100.

[24] Gneezy, U. and A. Rustichini (2000) Pay Enough or Don't Pay at All, The Quarterly Journal of Economics, 115 (3), 791-810.

[25] Green, J., and N. Stokey (1983) A Comparison of Tournaments and Contracts, Journal of Political Economy, 91(3), 349- 364. 
[26] Gragnolati, M., Shekar, M., Gupta, M.D., Bredenkamp, C., Lee, Y.K. (2005) India's Undernourished Children: A Call for Reform and Action. HNP World Bank Discussion Paper.

[27] Hasnain, Z., N. Manning, J. Pierskalla (2012) Performance-related Pay in the Public Sector : A Review of Theory and Evidence, World Bank Policy Research Working Paper No. WPS6043.

[28] HUNGaMA Survey Report (2011) The Hunger and Malnutrition (HUNGaMA) Survey Report 2011, The Naandi Foundation.

[29] ICDS Guidelines (2007) Ministry of Women and Child Development, Government of India. Available at: http://wcd.nic.in. Last accessed on September 28th, 2013.

[30] Imbens, G.W., Wooldridge, J.M. (2009) Recent Developments in the Econometrics of Program Evaluation. Journal of Economic Literature 47, Issue 1, 5-86.

[31] Imbens, G.W., Rubin, D.B. (1997) Bayesian Inference for Causal Effects in Randomized Experiments with Noncompliance. Annals of Statistics 25, 305-327.

[32] IGC Report (2013) Assessment of Bihar's ICDS Supplementary Nutrition Programme, IDinsight, available at: $<$ http://www.theigc.org/events/assessment-bihar\%E2\%80\%99s-icdssupplementary-nutrition-programme $>$

[33] Kingdon, G. and S. Rawal (2010) Akin to My Teacher: Does Caste, Religious and Gender Distance Between Student and Teacher Matter? Some Evidence from India. Department of Quantitative Social Science Working Paper 10-18, Institute of Education, University of London.

[34] Lazear, E. (2000) The Power of Incentives, American Economic Review, 90(2), 410-414. 
[35] Lazear, E. and S. Rosen (1981) Rank-Order Tournaments as Optimum Labor Contracts, Journal of Political Economy, 89(5), 841-864.

[36] Lee, D. (2009) Training, Wages, and Sample Selection: Estimating Sharp Bounds on Treatment Effects, Review of Economic Studies, 76(3): 1071-1102.

[37] Lok Sabha (2012) Unstarred Question No. 1343, 21.03.2012. available on IndiaStat.com

[38] Miller, G. and K. Babiarz (2013) Pay-For-Performance Incentives in Low- and Middle-Income Country Health Programs, NBER Working Paper No. 18932.

[39] Miller, G., R. Luo, L. Zhang, S. Sylvia, Y. Shi, P. Foo, Q. Zhao, R. Martorell, A. Medina, S. Rozelle (2012) Effectiveness of provider incentives for anaemia reduction in rural China: a cluster randomised trial, $B M J$, $345, \mathrm{e} 4809$.

[40] Mullen, K., R. G. Frank, M. B. Rosenthal (2010) Can you get what you pay for? Pay-for-performance and the quality of healthcare providers. RAND Journal of Economics, RAND Corporation, vol. 41(1), pages 64-91

[41] Moulton B.R. (1986) Random Group Effects and the Precision of Regression Estimates, Journal of Econometrics 32, 385-397.

[42] Norton, E.C. (1992) Incentive regulation of nursing homes, Journal of Health Economics, 11, 105-128.

[43] Pelletier, D.L., Frongillo Jr., E.A., Schroeder, D.G., Habicht, J.P. (1995) The effects of malnutrition on child mortality in developing countries. Bulletin of the World Health Organization 73, 443-448. 
[44] Petersen, L.A., Woodard, L.D, Urech, T., Daw, C., Sookanan, S. (2006) Does Pay-for-Performance Improve the Quality of Health Care? Annals of Internal Medicine 145, 265-272.

[45] Prendergast, C. (1999) The Provision of Incentives in Firms. Journal of Economic Literature 37, 7-63.

[46] Rajya Sabha (2011) Unstarred Question No. 2808, 19.12.2011. available on IndiaStat.com

[47] Singh, P. (2015) Performance Pay and Information: Reducing Child Undernutrition in India. Journal of Economic Behavior \&3 Organization, Volume 112, April, Pages 141-163.

[48] Tauchmann, H. (2012) Lee bounds: Stata module for estimating Lee (2009) treatment effect bounds, Boston College Department of Economics Working Paper.

[49] WHO (2007) The WHO Child Growth Reference Standards. Available at: <http://www.who.int/childgrowth/en>.

\section{$9 \quad$ Tables and Figures}

\begin{tabular}{lrr}
\multicolumn{2}{c}{$\begin{array}{c}\text { Table 1: Distribution of clusters and centers by treatment } \\
\text { Total clusters }\end{array}$} & Total centers \\
\hline Basic Absolute Treatment & 8 & 50 \\
High Absolute Treatment & 8 & 53 \\
Basic Relative Treatment & 8 & 55 \\
Control group & 10 & 51
\end{tabular}


Table 2: Summary statistics at baseline

\begin{tabular}{|c|c|c|c|c|c|c|c|}
\hline \multirow[b]{2}{*}{ Variables } & \multirow[b]{2}{*}{$\mathrm{BA}$} & \multirow[b]{2}{*}{$\mathrm{HA}$} & \multirow[b]{2}{*}{$\mathrm{BR}$} & \multirow[b]{2}{*}{ C } & \multicolumn{3}{|c|}{ Normalized Differences } \\
\hline & & & & & BA-C & $\mathrm{HA}-\mathrm{C}$ & BR-C \\
\hline \multirow[t]{2}{*}{ Mother's age } & 28.09 & 27.64 & 27.38 & 27.47 & 0.08 & 0.02 & -0.01 \\
\hline & {$[5.11]$} & {$[5.43]$} & [5.23] & [5.67] & & & \\
\hline \multirow[t]{2}{*}{ Mother can read } & 0.73 & 0.67 & 0.75 & 0.73 & 0.00 & -0.09 & 0.03 \\
\hline & {$[0.44]$} & {$[0.47]$} & {$[0.43]$} & {$[0.44]$} & & & \\
\hline \multirow[t]{2}{*}{ Monthly income } & 4556.27 & 4059.73 & 4400.02 & 3867.94 & 0.19 & 0.05 & 0.19 \\
\hline & [2608.34] & [2567.92] & [2823.25] & [2513.68] & & & \\
\hline \multirow[t]{2}{*}{ Number of rooms } & 1.43 & 1.39 & 1.43 & 1.40 & 0.02 & -0.01 & 0.02 \\
\hline & [1.08] & {$[0.88]$} & {$[0.90]$} & {$[0.87]$} & & & \\
\hline \multirow[t]{2}{*}{ Mobile phone } & 0.84 & 0.66 & 0.83 & 0.66 & 0.30 & 0.00 & 0.28 \\
\hline & {$[0.37]$} & {$[0.47]$} & {$[0.37]$} & {$[0.47]$} & & & \\
\hline \multirow[t]{2}{*}{ Water tap at home } & 0.35 & 0.14 & 0.18 & 0.14 & 0.35 & 0.00 & 0.08 \\
\hline & {$[0.48]$} & {$[0.35]$} & [0.39] & {$[0.35]$} & & & \\
\hline \multirow[t]{2}{*}{ Weight of child } & 13.65 & 13.45 & 13.62 & 13.49 & 0.05 & -0.01 & 0.04 \\
\hline & {$[2.05]$} & [2.09] & {$[2.28]$} & {$[2.10]$} & & & \\
\hline \multirow[t]{2}{*}{ Age of child } & 4.23 & 4.21 & 4.23 & 4.18 & 0.04 & 0.03 & 0.04 \\
\hline & {$[0.83]$} & {$[0.84]$} & {$[0.81]$} & {$[0.85]$} & & & \\
\hline \multirow[t]{2}{*}{ Fraction female } & 0.51 & 0.52 & 0.50 & 0.50 & 0.01 & 0.03 & 0.00 \\
\hline & {$[0.50]$} & {$[0.50]$} & {$[0.50]$} & {$[0.50]$} & & & \\
\hline \multirow[t]{2}{*}{ Total Siblings } & 1.29 & 1.15 & 1.21 & 1.43 & -0.07 & -0.15 & -0.12 \\
\hline & {$[1.35]$} & [1.29] & {$[1.26]$} & {$[1.30]$} & & & \\
\hline \multirow[t]{2}{*}{ Toilet in AWC } & 0.39 & 0.30 & 0.49 & 0.39 & 0.00 & -0.13 & 0.14 \\
\hline & {$[0.48]$} & {$[0.46]$} & {$[0.50]$} & {$[0.49]$} & & & \\
\hline \multirow[t]{2}{*}{ Drinking water in AWC } & 0.68 & 0.67 & 0.80 & 0.74 & -0.09 & -0.11 & 0.10 \\
\hline & {$[0.47]$} & {$[0.47]$} & {$[0.40]$} & {$[0.44]$} & & & \\
\hline
\end{tabular}

Notes: Standard deviations in parenthesis. Normalized differences are calculated using the formula as in Imbens and Wooldridge (2009) for a scale-free measure of the difference in distributions. A rule of thumb is that when normalized difference exceeds 0.25 in absolute value, linear regression methods tend to be sensitive to the specification (Imbens and Rubin (2007)).

Table 3: Attrition rates in children across groups

\begin{tabular}{lllll}
\hline & BA & HA & BR & C \\
Baseline children & 1333 & 1555 & 1369 & 1264 \\
Endline children & 971 & 1127 & 1031 & 933 \\
Attrition (\%) & 0.27 & 0.28 & 0.25 & 0.26
\end{tabular}




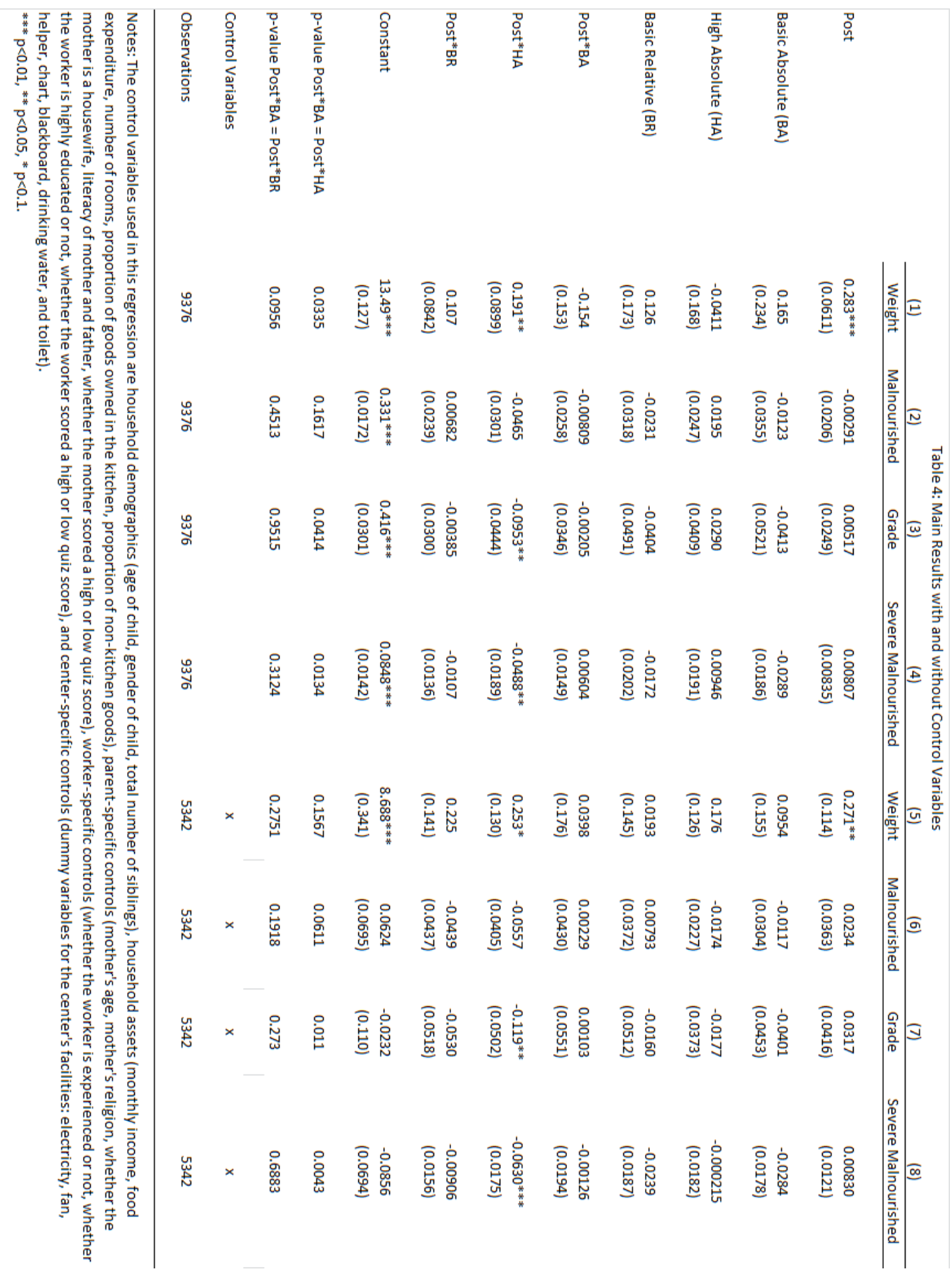


Table 5: Effect of propensity matching on change in weight for the high absolute treatment

\begin{tabular}{|c|c|c|c|c|c|}
\hline & Treated & Controls & Difference & Standard Error & T-statistic \\
\hline Unmatched & 0.567 & 0.387 & 0.180 & 0.060 & 2.99 \\
\hline ATT & 0.570 & 0.401 & 0.170 & 0.063 & 2.69 \\
\hline
\end{tabular}

Panel B: Kernel matching

\begin{tabular}{lccccc}
\hline & Treated & Controls & Difference & Standard Error & T-statistic \\
\cline { 2 - 6 } Unmatched & 0.567 & 0.387 & 0.180 & 0.060 & 2.99 \\
ATT & 0.567 & 0.389 & 0.178 & 0.060 & 2.95
\end{tabular}

Panel C: Radius matching

\begin{tabular}{lccccc}
\hline & Treated & Controls & Difference & Standard Error & T-statistic \\
\cline { 2 - 6 } Unmatched & 0.567 & 0.387 & 0.180 & 0.060 & 2.99 \\
ATT & 0.567 & 0.388 & 0.180 & 0.060 & 2.98
\end{tabular}


Table 6: Checking reversion to the mean

\begin{tabular}{|c|c|c|}
\hline & $\begin{array}{c}\text { Weight at endline } \\
\text { (1) }\end{array}$ & $\begin{array}{c}\text { Weight at endline } \\
\text { (2) }\end{array}$ \\
\hline Weight at baseline & $\begin{array}{l}0.800^{* * *} \\
(0.0455)\end{array}$ & $\begin{array}{l}0.799 * * * \\
(0.0454)\end{array}$ \\
\hline Basic Absolute (BA) & $\begin{array}{c}0.133 \\
(0.113)\end{array}$ & $\begin{array}{c}0.134 \\
(0.112)\end{array}$ \\
\hline High Absoute (HA) & $\begin{array}{l}0.375^{* * *} \\
(0.0894)\end{array}$ & $\begin{array}{l}0.377^{* * *} \\
(0.0893)\end{array}$ \\
\hline Basic Relative (BR) & $\begin{array}{c}0.193 \\
(0.115)\end{array}$ & $\begin{array}{l}0.195^{*} \\
(0.115)\end{array}$ \\
\hline Age of child & & Yes \\
\hline Age of child squared & & Yes \\
\hline Control variables & Yes & Yes \\
\hline$p$-value $(H A-B A=0)$ & 0.014 & 0.013 \\
\hline$p$-value $(B R-B A=0)$ & 0.594 & 0.593 \\
\hline Constant & $\begin{array}{c}1.710^{* * *} \\
(0.477)\end{array}$ & $\begin{array}{c}2.136^{* * *} \\
(0.719)\end{array}$ \\
\hline $\begin{array}{l}\text { Observations } \\
\text { R-squared }\end{array}$ & $\begin{array}{l}4649 \\
0.669\end{array}$ & $\begin{array}{l}4649 \\
0.669\end{array}$ \\
\hline
\end{tabular}

Notes: The control variables used in this regression are household demographics (age of child, gender of child, total number of siblings), household assets (monthly income, food expenditure, number of rooms, proportion of goods owned in the kitchen, proportion of non-kitchen goods), parent-specific controls (mother's age, mother's religion, whether the mother is a housewife, literacy of mother and father, whether the mother scored a high or low quiz score), worker-specific controls (whether the worker is experienced or not, whether the worker is highly educated or not, whether the worker scored a high or low quiz score), and center-specific controls (dummy variables for the center's facilities: electricity, fan, helper, chart, blackboard, drinking water, and toilet).

*** $p<0.01,{ }^{* *} p<0.05, * p<0.1$. 
Table 7: Lee (2009) treatment effect bounds on change in weight

$\begin{array}{ll}\text { Number of observations } & =3657 \\ \text { Number of selected observations } & =2054 \\ \text { Number of cells } & =16 \\ \text { Overall trimming proportion } & =0.1413 \\ \text { Effect 95\% conf. interval } & :[-0.0077,0.3823]\end{array}$

\begin{tabular}{|c|c|c|c|c|c|c|}
\hline Change in weight & $\begin{array}{c}\text { Observed } \\
\text { Coef. }\end{array}$ & $\begin{array}{c}\text { Bootstrap } \\
\text { Std. Err. }\end{array}$ & z & $P>|z|$ & \multicolumn{2}{|c|}{$\begin{array}{l}\text { Normal-based } \\
\text { [95\% Conf. } \\
\text { Interval] }\end{array}$} \\
\hline $\begin{array}{l}\text { High absolute } \\
\text { treatment }\end{array}$ & & & & & & \\
\hline lower & 0.157 & 0.093 & 1.70 & 0.090 & -0.024 & 0.339 \\
\hline upper & 0.204 & 0.100 & 2.03 & 0.042 & 0.007 & 0.400 \\
\hline
\end{tabular}

Notes: The number of cells is based on tightening the Lee bounds using the gender of child, mother's literacy, father's literacy and religion (Hindu/Muslim) indicator variables. Adding more control variables was not possible with implementation of the bounds in STATA. 


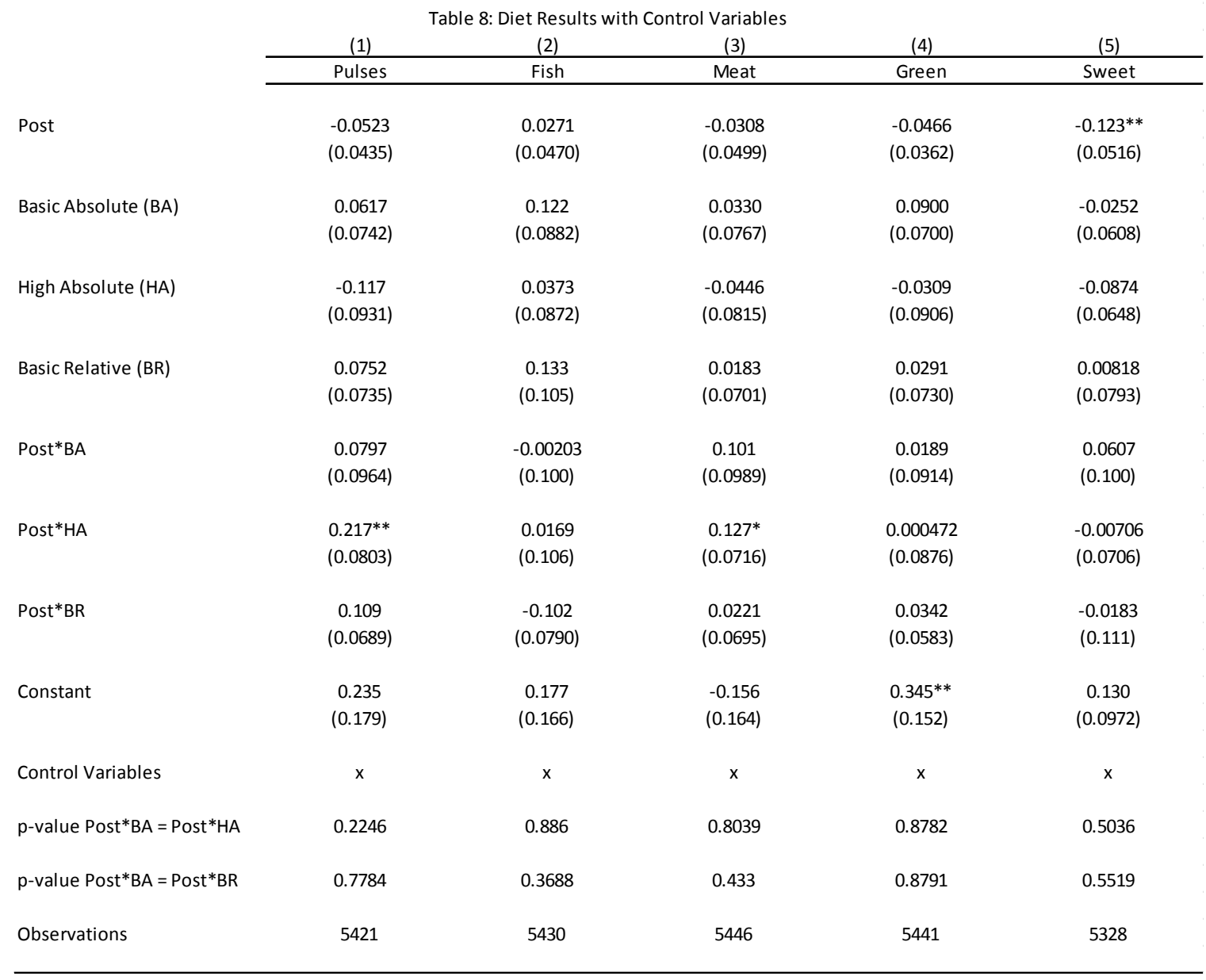

Notes: The control variables used in this regression are household demographics (age of child, gender of child, total number of siblings), household assets (monthly income, food expenditure, number of rooms, proportion of goods owned in the kitchen, proportion of nonkitchen goods), parent-specific controls (mother's age, mother's religion, whether the mother is a housewife, literacy of mother and father, whether the mother scored a high or low quiz score), worker-specific controls (whether the worker is experienced or not, whether the worker is highly educated or not, whether the worker scored a high or low quiz score), and center-specific controls (dummy variables for the center's facilities: electricity, fan, helper, chart, blackboard, drinking water, and toilet).

$* * * p<0.01, * * p<0.05, * p<0.1$. 
Table 9: Gender Difference in average treatment effects

\begin{tabular}{|c|c|c|c|c|}
\hline & (1) & (2) & (3) & (4) \\
\hline & Weight & Malnourished & Grade & Severe Malnourished \\
\hline \multirow[t]{2}{*}{ Post*BA } & 0.142 & -0.0226 & -0.0339 & -0.0113 \\
\hline & (0.216) & $(0.0428)$ & $(0.0712)$ & $(0.0391)$ \\
\hline \multirow[t]{2}{*}{ Post*HA } & $0.432 * * *$ & $-0.0989 * *$ & $-0.191 * * *$ & $-0.0924 * *$ \\
\hline & $(0.145)$ & $(0.0397)$ & $(0.0620)$ & $(0.0350)$ \\
\hline \multirow[t]{2}{*}{ Post*BR } & 0.219 & -0.0548 & -0.0682 & -0.0133 \\
\hline & $(0.164)$ & $(0.0371)$ & (0.0548) & $(0.0307)$ \\
\hline \multirow[t]{2}{*}{ Gender*BA*Post } & -0.197 & 0.0475 & 0.0678 & 0.0203 \\
\hline & $(0.163)$ & $(0.0469)$ & $(0.0887)$ & $(0.0548)$ \\
\hline \multirow[t]{2}{*}{ Gender*HA*Post } & $-0.345^{*}$ & $0.0830 *$ & $0.140^{*}$ & 0.0567 \\
\hline & (0.193) & $(0.0483)$ & $(0.0780)$ & $(0.0435)$ \\
\hline \multirow[t]{2}{*}{ Gender*BR*Post } & 0.0188 & 0.0202 & 0.0283 & 0.00811 \\
\hline & $(0.176)$ & $(0.0426)$ & $(0.0726)$ & $(0.0424)$ \\
\hline \multirow[t]{2}{*}{ Constant } & $8.784 * * *$ & 0.0442 & -0.0635 & -0.108 \\
\hline & $(0.349)$ & (0.0699) & (0.109) & $(0.0708)$ \\
\hline Control Variables & $x$ & $x$ & $x$ & $x$ \\
\hline Observations & 5342 & 5342 & 5342 & 5342 \\
\hline
\end{tabular}

Notes: Gender = 1 if girl and 0 if boy. The control variables used in this regression are household demographics (age of child, gender of child, total number of siblings), household assets (monthly income, food expenditure, number of rooms, proportion of goods owned in the kitchen, proportion of non-kitchen goods), parent-specific controls (mother's age, mother's religion, whether the mother is a housewife, literacy of mother and father, whether the mother scored a high or low quiz score), worker-specific controls (whether the worker is experienced or not, whether the worker is highly educated or not, whether the worker scored a high or low quiz score), and center-specific controls (dummy variables for the center's facilities: electricity, fan, helper, chart, blackboard, drinking water, and toilet).

$* * * p<0.01, * * p<0.05, * p<0.1$. 


\begin{tabular}{|c|c|c|c|c|c|c|}
\hline & $(1)$ & $(2)$ & $(3)$ & (4) & $(5)$ & $(6)$ \\
\hline & All sample & Age 3-4 & Age 4-5 & Age 5-6 & Boys & Girls \\
\hline Post & $\begin{array}{c}0.175 * * * \\
(0.0352)\end{array}$ & $\begin{array}{c}0.237 * * * \\
(0.0427)\end{array}$ & $\begin{array}{c}0.119 * \\
(0.0600)\end{array}$ & $\begin{array}{l}0.104 * * \\
(0.0484)\end{array}$ & $\begin{array}{c}0.143^{* * *} \\
(0.0478)\end{array}$ & $\begin{array}{c}0.206 * * * \\
(0.0420)\end{array}$ \\
\hline Basic Absolute (BA) & $\begin{array}{c}0.0481 \\
(0.0959)\end{array}$ & $\begin{array}{l}0.0958 \\
(0.123)\end{array}$ & $\begin{array}{l}-0.0484 \\
(0.0880)\end{array}$ & $\begin{array}{c}0.155 \\
(0.161)\end{array}$ & $\begin{array}{l}0.0294 \\
(0.115)\end{array}$ & $\begin{array}{c}0.0662 \\
(0.0873)\end{array}$ \\
\hline High Absolute (HA) & $\begin{array}{l}-0.0308 \\
(0.0679)\end{array}$ & $\begin{array}{l}-0.00457 \\
(0.0802)\end{array}$ & $\begin{array}{l}-0.0184 \\
(0.0691)\end{array}$ & $\begin{array}{l}-0.0724 \\
(0.113)\end{array}$ & $\begin{array}{l}-0.0637 \\
(0.105)\end{array}$ & $\begin{array}{l}0.00165 \\
(0.0562)\end{array}$ \\
\hline Basic Relative (BR) & $\begin{array}{c}0.0375 \\
(0.0744)\end{array}$ & $\begin{array}{l}0.00130 \\
(0.0752)\end{array}$ & $\begin{array}{c}0.0224 \\
(0.0879)\end{array}$ & $\begin{array}{c}0.143 \\
(0.135)\end{array}$ & $\begin{array}{c}0.0222 \\
(0.0905)\end{array}$ & $\begin{array}{c}0.0519 \\
(0.0748)\end{array}$ \\
\hline Post*BA & $\begin{array}{l}-0.00448 \\
(0.0611)\end{array}$ & $\begin{array}{l}-0.0986 \\
(0.0767)\end{array}$ & $\begin{array}{c}0.103 \\
(0.0845)\end{array}$ & $\begin{array}{l}-0.0389 \\
(0.0962)\end{array}$ & $\begin{array}{c}0.0284 \\
(0.0745)\end{array}$ & $\begin{array}{l}-0.0368 \\
(0.0635)\end{array}$ \\
\hline Post*HA & $\begin{array}{c}0.107^{*} \\
(0.0535)\end{array}$ & $\begin{array}{c}0.0681 \\
(0.0713)\end{array}$ & $\begin{array}{l}0.162^{* *} \\
(0.0682)\end{array}$ & $\begin{array}{c}0.0948 \\
(0.0962)\end{array}$ & $\begin{array}{c}0.203^{* * *} \\
(0.0675)\end{array}$ & $\begin{array}{c}0.0191 \\
(0.0627)\end{array}$ \\
\hline Post*BR & $\begin{array}{c}0.0493 \\
(0.0476)\end{array}$ & $\begin{array}{c}0.0494 \\
(0.0644)\end{array}$ & $\begin{array}{c}0.0355 \\
(0.0714)\end{array}$ & $\begin{array}{c}0.102 \\
(0.0938)\end{array}$ & $\begin{array}{c}0.0531 \\
(0.0669)\end{array}$ & $\begin{array}{c}0.0462 \\
(0.0504)\end{array}$ \\
\hline Constant & $\begin{array}{c}-1.433^{* * *} \\
(0.0498)\end{array}$ & $\begin{array}{c}-1.309^{* * *} \\
(0.0483)\end{array}$ & $\begin{array}{c}-1.477^{* * *} \\
(0.0579)\end{array}$ & $\begin{array}{c}-1.647^{* * *} \\
(0.0658)\end{array}$ & $\begin{array}{c}-1.395^{* * *} \\
(0.0690)\end{array}$ & $\begin{array}{c}-1.470^{* * *} \\
(0.0428)\end{array}$ \\
\hline $\begin{array}{l}\text { Observations } \\
\text { R-squared }\end{array}$ & $\begin{array}{l}9377 \\
0.014\end{array}$ & $\begin{array}{l}4164 \\
0.016\end{array}$ & $\begin{array}{l}3383 \\
0.014\end{array}$ & $\begin{array}{l}1720 \\
0.016\end{array}$ & $\begin{array}{l}4581 \\
0.013\end{array}$ & $\begin{array}{l}4796 \\
0.015\end{array}$ \\
\hline
\end{tabular}

*** $p<0.01,{ }^{* *} p<0.05,{ }^{*} p<0.1$. 
Table 11: Selective targeting test

$\begin{array}{cccc}(1) & (2) & (3) & \text { (4) } \\ \text { Weight } & \text { Malnourished } & \text { Grade } & \text { Severe Malnour }\end{array}$

Severe Malnourished

\begin{tabular}{|c|c|c|c|c|}
\hline Post*BA & $\begin{array}{c}-0.0206 \\
(0.158)\end{array}$ & $\begin{array}{c}0.0526 \\
(0.0619)\end{array}$ & $\begin{array}{c}0.0892 \\
(0.0799)\end{array}$ & $\begin{array}{c}0.0366 \\
(0.0463)\end{array}$ \\
\hline Post*HA & $\begin{array}{l}0.469 * * \\
(0.181)\end{array}$ & $\begin{array}{l}-0.109 * \\
(0.0623)\end{array}$ & $\begin{array}{c}-0.301 * * * \\
(0.0778)\end{array}$ & $\begin{array}{c}-0.193^{* * *} \\
(0.0410)\end{array}$ \\
\hline Post*BR & $\begin{array}{c}0.0483 \\
(0.194)\end{array}$ & $\begin{array}{c}-0.00445 \\
(0.0760)\end{array}$ & $\begin{array}{l}-0.0204 \\
(0.102)\end{array}$ & $\begin{array}{l}-0.0159 \\
(0.0359)\end{array}$ \\
\hline Close To Target*BA*Post & $\begin{array}{l}0.0700 \\
(0.216)\end{array}$ & $\begin{array}{l}-0.0862 \\
(0.0967)\end{array}$ & $\begin{array}{r}-0.116 \\
(0.110)\end{array}$ & $\begin{array}{l}-0.0293 \\
(0.0533)\end{array}$ \\
\hline Close To Target*HA*Post & $\begin{array}{c}0.239 \\
(0.212)\end{array}$ & $\begin{array}{c}0.0207 \\
(0.0915)\end{array}$ & $\begin{array}{c}0.0582 \\
(0.0914)\end{array}$ & $\begin{array}{c}0.0375 \\
(0.0447)\end{array}$ \\
\hline Close To Target*BR*Post & $\begin{array}{l}0.0265 \\
(0.299)\end{array}$ & $\begin{array}{r}-0.0522 \\
(0.126)\end{array}$ & $\begin{array}{c}-0.0670 \\
(0.162)\end{array}$ & $\begin{array}{l}-0.0148 \\
(0.0670)\end{array}$ \\
\hline Constant & $\begin{array}{c}5.987^{* * *} \\
(0.415)\end{array}$ & $\begin{array}{l}1.162^{* * *} \\
(0.0835)\end{array}$ & $\begin{array}{c}1.104^{* * *} \\
(0.210)\end{array}$ & $\begin{array}{c}-0.0584 \\
(0.191)\end{array}$ \\
\hline $\begin{array}{l}\text { Control Variables } \\
\text { Observations }\end{array}$ & $\begin{array}{c}x \\
1739\end{array}$ & $\begin{array}{c}x \\
1739\end{array}$ & $\begin{array}{c}x \\
1739\end{array}$ & $\begin{array}{c}x \\
1739\end{array}$ \\
\hline $\begin{array}{l}\text { Notes: The control variab } \\
\text { number of siblings), hous } \\
\text { owned in the kitchen, pro } \\
\text { whether the mother is a } \\
\text { score), worker-specific co } \\
\text { or not, whether the work } \\
\text { center's facilities: electric } \\
\text { regression include treatm } \\
\text { close to target with post. } \\
\text { its deficit weight (differe } \\
\text { and } 0 \text { if the child is malno } \\
\text { deficit weight. Target wei } \\
\text { from severely malnourish } \\
\text { malnourished). }\end{array}$ & $\begin{array}{l}\text { in column } \\
\text { ssets (mon } \\
\text { of non-kit } \\
\text { ife, literac) } \\
\text { whether th } \\
\text { d a high or } \\
\text { helper, ch } \\
\text { their own } \\
\text { iable close } \\
\text { ween the t } \\
\text { at the bas } \\
\text { efined as } t \\
\text { nly moder }\end{array}$ & $\begin{array}{l}\text { household } \\
\text {, food exp } \\
\text { ), parent-sf } \\
\text { and father, } \\
\text { experienc } \\
\text { ore), and ce } \\
\text { ard, drinki } \\
\text { get on its } \\
\text { efined to b } \\
\text { t and the a } \\
\text { s or her de } \\
\text { d at which } \\
\text { urished or }\end{array}$ & $\begin{array}{l}\text { hics (age of } \\
\text { umber of ro } \\
\text { rols (mothe } \\
\text { he mother s } \\
\text { hether the } \\
\text { fic controls } \\
\text { nd toilet). O } \\
n \text { its own an } \\
\text { ild is malno } \\
\text { t) is less tha } \\
\text { is more tha } \\
\text { rade will de } \\
\text { rately malnc }\end{array}$ & $\begin{array}{l}\text { er of child, total } \\
\text { rtion of goods } \\
\text { cher's religion, } \\
\text { n or low quiz } \\
\text { ighly educated } \\
\text { riables for the } \\
\text { les in this } \\
\text { interactions of } \\
\text { the baseline and } \\
\text { deficit weight } \\
\text { to the mean } \\
\text { (i.e. would go } \\
\text { not }\end{array}$ \\
\hline
\end{tabular}


Table 12: Dose response check in terms of proportion of malnourished children

\begin{tabular}{|c|c|c|c|c|c|}
\hline & $(1)$ & $(2)$ & (3) & (4) & $(5)$ \\
\hline & Weight & z-score & Grade & Malnourished & Severe Malnourished \\
\hline \multirow[t]{2}{*}{ Post } & -0.0867 & -0.00781 & $0.196 * *$ & $0.161^{* *}$ & 0.0349 \\
\hline & $(0.180)$ & $(0.0963)$ & $(0.0877)$ & $(0.0670)$ & $(0.0279)$ \\
\hline \multirow[t]{2}{*}{ Post*HA } & -0.283 & -0.172 & 0.0791 & 0.0234 & 0.0557 \\
\hline & $(0.382)$ & (0.199) & $(0.118)$ & $(0.0893)$ & (0.0349) \\
\hline \multirow[t]{2}{*}{ Dose*HA*Post } & $1.669 *$ & $0.909 *$ & $-0.613 * *$ & -0.253 & $-0.361 * * *$ \\
\hline & $(0.956)$ & $(0.485)$ & $(0.269)$ & $(0.207)$ & $(0.0970)$ \\
\hline Control Variables & $x$ & $x$ & $x$ & $x$ & $x$ \\
\hline \multirow[t]{2}{*}{ Constant } & $9.541 * * *$ & -0.191 & $-0.353^{* * *}$ & $-0.163^{* * *}$ & $-0.190 * *$ \\
\hline & -0.355 & -0.159 & -0.111 & -0.059 & -0.0743 \\
\hline Observations & 5342 & 5342 & 5342 & 5342 & 5342 \\
\hline R-squared & 0.308 & 0.163 & 0.133 & 0.116 & 0.076 \\
\hline \multicolumn{6}{|c|}{$\begin{array}{l}\text { Notes: Dose represents the number of malnourished children divided by the total number of children weighed at the baseline in the Anganwadi } \\
\text { (i.e. the proportion of malnourished children at the baseline in the center). The control variables used in this regression are BA, BR, Post*BA, } \\
\text { Post*BR, household demographics (age of child, gender of child, total number of siblings), household assets (monthly income, food expenditure, } \\
\text { number of rooms, proportion of goods owned in the kitchen, proportion of non-kitchen goods), parent-specific controls (mother's age, mother's } \\
\text { religion, whether the mother is a housewife, literacy of mother and father, whether the mother scored a high or low quiz score), worker-specific } \\
\text { controls (whether the worker is experienced or not, whether the worker is highly educated or not, whether the worker scored a high or low quiz } \\
\text { score), and center-specific controls (dummy variables for the center's facilities: electricity, fan, helper, chart, blackboard, drinking water, and } \\
\text { toilet). }\end{array}$} \\
\hline
\end{tabular}

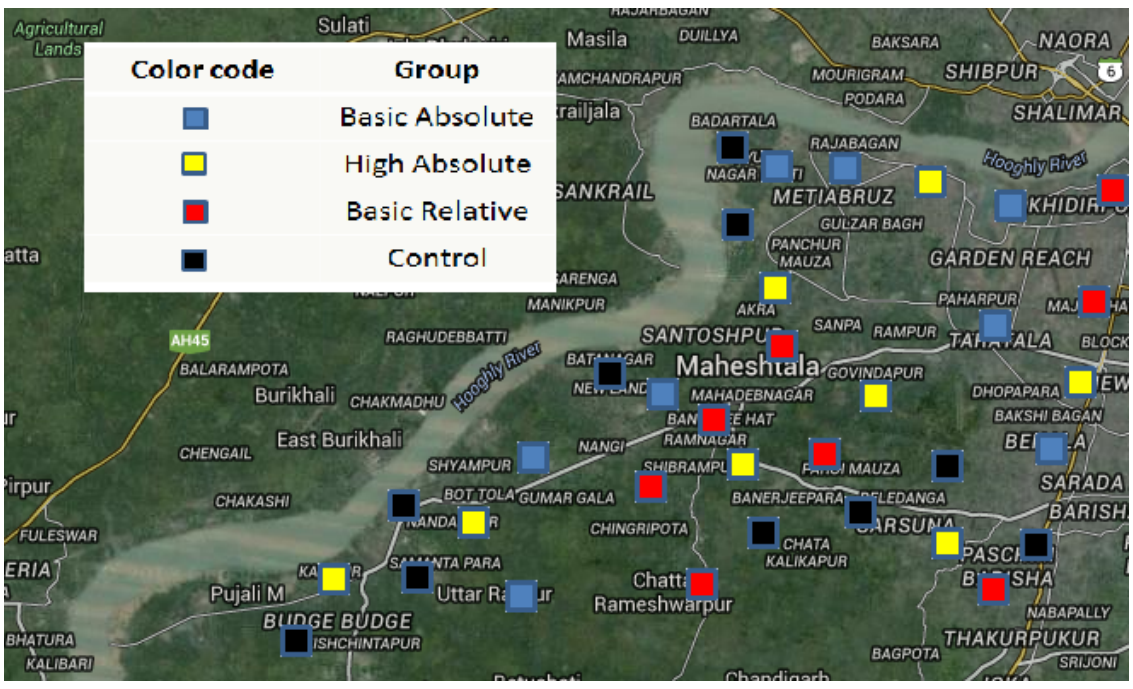

Figure 1: Map of Maheshtala showing geographical distribution of

treatments 


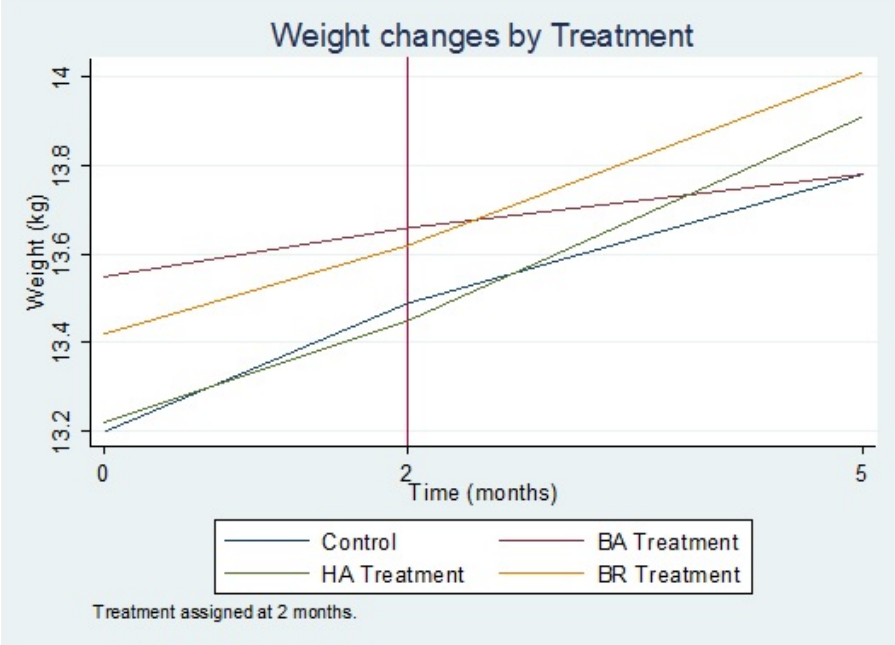

Figure 2: Weight changes by Treatment 


\section{Appendix}

\subsection{Tables}

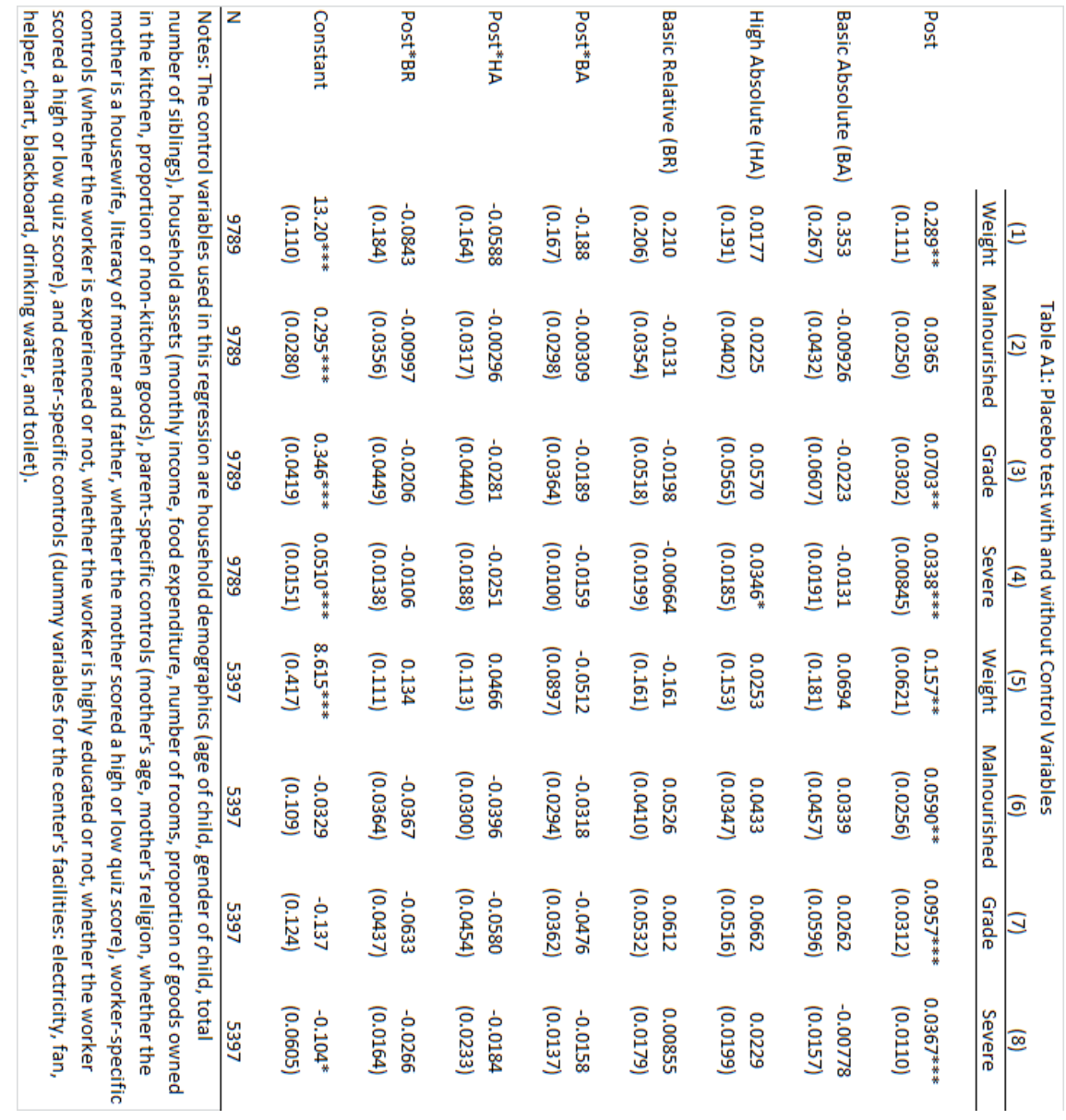




\begin{tabular}{|c|c|c|c|c|}
\hline & (1) & $\begin{array}{c}\text { ttrition Tabl } \\
\text { (2) }\end{array}$ & (3) & (4) \\
\hline \multirow[b]{2}{*}{ Weight*BA } & Attrition & Attrition & Attrition & Attrition \\
\hline & $\begin{array}{c}0.0190 \\
(0.0155)\end{array}$ & & & \\
\hline Weight*HA & $\begin{array}{l}-0.00657 \\
(0.0152)\end{array}$ & & & \\
\hline Weight*BR & $\begin{array}{l}-0.00680 \\
(0.0169)\end{array}$ & & & \\
\hline Malnourished*BA & & $\begin{array}{l}-0.0367 \\
(0.0656)\end{array}$ & & \\
\hline Malnourished*HA & & $\begin{array}{c}0.0314 \\
(0.0532)\end{array}$ & & \\
\hline Malnourished*BR & & $\begin{array}{c}0.0114 \\
(0.0695)\end{array}$ & & \\
\hline Grade*BA & & & $\begin{array}{l}-0.0301 \\
(0.0555)\end{array}$ & \\
\hline Grade*HA & & & $\begin{array}{c}0.0114 \\
(0.0460)\end{array}$ & \\
\hline Grade*BR & & & $\begin{array}{l}-0.00393 \\
(0.0603)\end{array}$ & \\
\hline SevereMalnourished*BA & & & & $\begin{array}{l}-0.0204 \\
(0.104)\end{array}$ \\
\hline SevereMalnourished*HA & & & & $\begin{array}{l}-0.0297 \\
(0.101)\end{array}$ \\
\hline SevereMalnourished*BR & & & & $\begin{array}{l}-0.0403 \\
(0.127)\end{array}$ \\
\hline Control Variables & $\mathrm{x}$ & $\mathrm{x}$ & $\mathrm{x}$ & $\mathrm{x}$ \\
\hline Observations & 3013 & 3013 & 3013 & 3013 \\
\hline \multicolumn{5}{|c|}{$\begin{array}{l}\text { Notes: The control variables used in this regression are household demographics (age of child, gender of child, total } \\
\text { number of siblings), household assets (monthly income, food expenditure, number of rooms, proportion of goods ownec } \\
\text { in the kitchen, proportion of non-kitchen goods), parent-specific controls (mother's age, mother's religion, whether the } \\
\text { mother is a housewife, literacy of mother and father, whether the mother scored a high or low quiz score), worker- } \\
\text { specific controls (whether the worker is experienced or not, whether the worker is highly educated or not, whether the } \\
\text { worker scored a high or low quiz score), and center-specific controls (dummy variables for the center's facilities: } \\
\text { electricity, fan, helper, chart, blackboard, drinking water, and toilet). The attrition variable takes value } 1 \text { if the child's } \\
\text { weight is unavailable in the second round, and } 0 \text { otherwise. } \\
{ }^{* * *} p<0.01,{ }^{* *} p<0.05,{ }^{*} p<0.1 \text {. }\end{array}$} \\
\hline
\end{tabular}


Table A3: Main Results with Control Variables and Moulton Correction

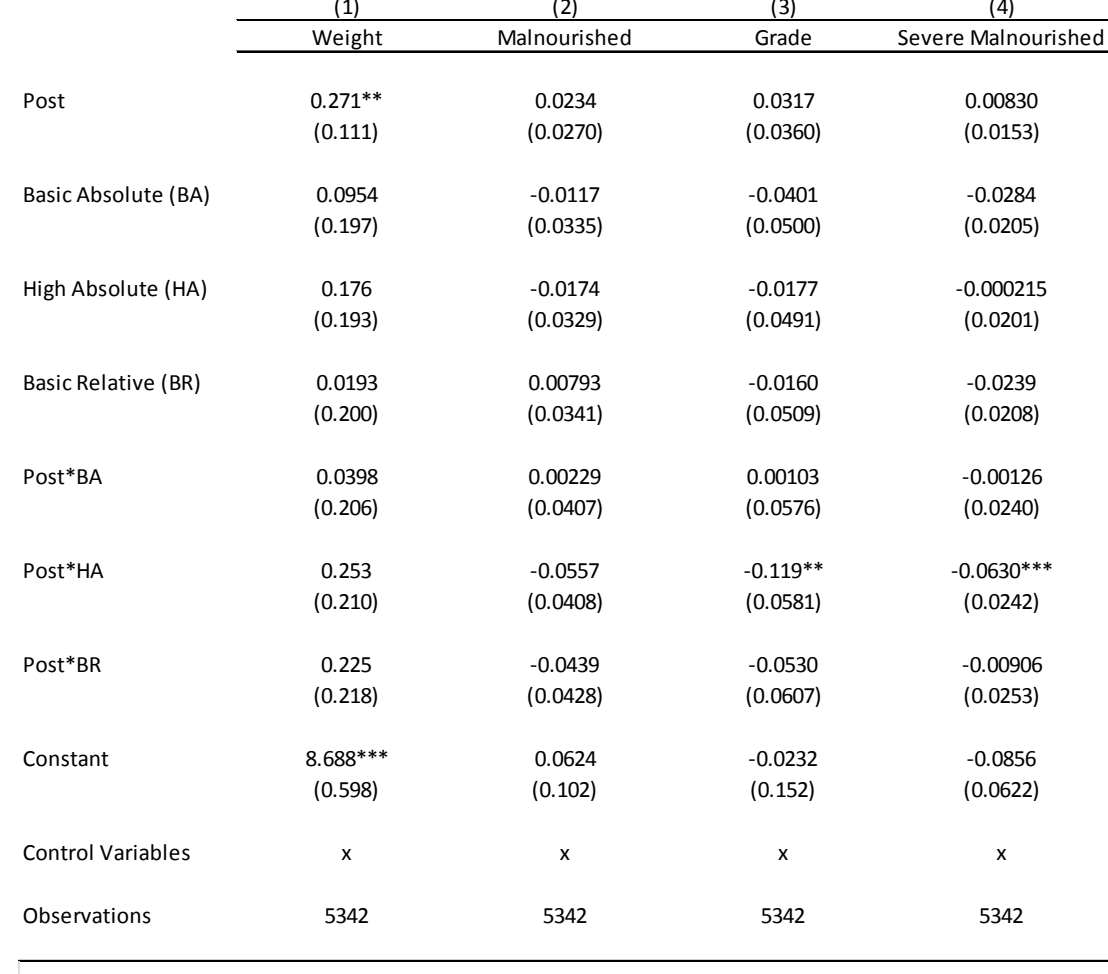

Notes: The control variables used in this regression are household demographics (age of child, gender of child, total number of siblings), household assets (monthly income, food expenditure, number of rooms, proportion of goods owned in the kitchen, proportion of non-kitchen goods), parent-specific controls (mother's age, mother's religion, whether the mother is a housewife, literacy of mother and father, whether the mother scored a high or low quiz score), worker-specific controls (whether the worker is experienced or not, whether the worker is highly educated or not, whether the worker scored a high or low quiz score), and center-specific controls (dummy variables for the center's facilities: electricity, fan, helper, chart, blackboard, drinking water, and toilet). Moulton correction for the standard errors is used in this table.

$* * * p<0.01, * * p<0.05, * p<0.1$. 
Table A4: Robustness Check for Main Results after excluding All Household Assets from Controls

\begin{tabular}{|c|c|c|c|c|}
\hline & (1) & $(2)$ & (3) & (4) \\
\hline & Weight & Malnourished & Grade & Severe Malnourished \\
\hline \multirow[t]{2}{*}{ Post } & $0.281^{* * *}$ & 0.0131 & 0.0114 & -0.00168 \\
\hline & $(0.0792)$ & $(0.0227)$ & $(0.0265)$ & $(0.00948)$ \\
\hline \multirow[t]{2}{*}{ Basic Absolute (BA) } & $0.281^{*}$ & -0.0498 & $-0.0915 * *$ & $-0.0417^{* * *}$ \\
\hline & $(0.164)$ & $(0.0317)$ & $(0.0441)$ & $(0.0152)$ \\
\hline \multirow[t]{2}{*}{ High Absolute (HA) } & 0.198 & -0.0299 & -0.0376 & -0.00769 \\
\hline & $(0.122)$ & $(0.0219)$ & $(0.0345)$ & $(0.0162)$ \\
\hline \multirow[t]{2}{*}{ Basic Relative (BR) } & 0.155 & -0.0323 & -0.0608 & $-0.0286^{*}$ \\
\hline & $(0.123)$ & $(0.0275)$ & $(0.0379)$ & $(0.0150)$ \\
\hline \multirow[t]{2}{*}{ Post*BA } & -0.00355 & 0.00528 & 0.0169 & 0.0116 \\
\hline & $(0.146)$ & $(0.0312)$ & $(0.0413)$ & $(0.0153)$ \\
\hline \multirow[t]{2}{*}{ Post*HA } & $0.263^{* * *}$ & $-0.0569 * *$ & $-0.109 * * *$ & $-0.0518^{* * *}$ \\
\hline & $(0.0844)$ & $(0.0252)$ & $(0.0342)$ & $(0.0156)$ \\
\hline \multirow[t]{2}{*}{ Post*BR } & 0.162 & -0.0277 & -0.0268 & 0.000865 \\
\hline & $(0.114)$ & $(0.0291)$ & $(0.0385)$ & $(0.0140)$ \\
\hline \multirow[t]{2}{*}{ Constant } & $8.840 * * *$ & 0.0519 & -0.0410 & $-0.0929 *$ \\
\hline & $(0.293)$ & $(0.0668)$ & $(0.0944)$ & $(0.0537)$ \\
\hline Control Variables & $\mathrm{x}$ & $\mathrm{x}$ & $\mathrm{x}$ & $\mathrm{x}$ \\
\hline$p$-value Post $* B A=$ Post $* H A$ & 0.0567 & 0.0266 & 0.0039 & 0.0019 \\
\hline $\mathrm{p}$-value Post*BA $=$ Post*BR & 0.2945 & 0.284 & 0.3301 & 0.5422 \\
\hline Observations & 6564 & 6564 & 6564 & 6564 \\
\hline \multicolumn{5}{|c|}{$\begin{array}{l}\text { Notes: The control variables used in this regression are household demographics (age of child, gender of child, total } \\
\text { number of siblings), parent-specific controls (mother's age, mother's religion, whether the mother is a housewife or not, } \\
\text { literacy of mother and father, whether the mother scored a high or low quiz score), worker-specific controls (whether } \\
\text { the worker is experienced or not, whether the worker is highly educated or not, whether the worker scored a high or low } \\
\text { quiz score), and center-specific controls (dummy variables for the center's facilities: electricity, fan, helper, chart, } \\
\text { blackboard, drinking water, and toilet). } \\
* * * p<0.01, * * p<0.05, * p<0.1 \text {. }\end{array}$} \\
\hline
\end{tabular}




\begin{tabular}{|c|c|c|c|c|c|c|}
\hline & (1) & $(2)$ & $(3)$ & (4) & (5) & (6) \\
\hline & All sample & Age 3-4 & Age 4-5 & Age 5-6 & Boys & Girls \\
\hline Post & $\begin{array}{c}0.175 * * * \\
(0.0352)\end{array}$ & $\begin{array}{c}0.237 * * * \\
(0.0427)\end{array}$ & $\begin{array}{c}0.119 * \\
(0.0600)\end{array}$ & $\begin{array}{l}0.104^{* *} \\
(0.0484)\end{array}$ & $\begin{array}{c}0.143 * * * \\
(0.0478)\end{array}$ & $\begin{array}{c}0.206 * * * \\
(0.0420)\end{array}$ \\
\hline Basic Absolute (BA) & $\begin{array}{c}0.0481 \\
(0.0959)\end{array}$ & $\begin{array}{l}0.0958 \\
(0.123)\end{array}$ & $\begin{array}{c}-0.0484 \\
(0.0880)\end{array}$ & $\begin{array}{c}0.155 \\
(0.161)\end{array}$ & $\begin{array}{l}0.0294 \\
(0.115)\end{array}$ & $\begin{array}{c}0.0662 \\
(0.0873)\end{array}$ \\
\hline High Absolute (HA) & $\begin{array}{c}-0.0308 \\
(0.0679)\end{array}$ & $\begin{array}{l}-0.00457 \\
(0.0802)\end{array}$ & $\begin{array}{c}-0.0184 \\
(0.0691)\end{array}$ & $\begin{array}{l}-0.0724 \\
(0.113)\end{array}$ & $\begin{array}{l}-0.0637 \\
(0.105)\end{array}$ & $\begin{array}{l}0.00165 \\
(0.0562)\end{array}$ \\
\hline Basic Relative (BR) & $\begin{array}{c}0.0375 \\
(0.0744)\end{array}$ & $\begin{array}{l}0.00130 \\
(0.0752)\end{array}$ & $\begin{array}{c}0.0224 \\
(0.0879)\end{array}$ & $\begin{array}{c}0.143 \\
(0.135)\end{array}$ & $\begin{array}{c}0.0222 \\
(0.0905)\end{array}$ & $\begin{array}{c}0.0519 \\
(0.0748)\end{array}$ \\
\hline Post*BA & $\begin{array}{l}-0.00448 \\
(0.0611)\end{array}$ & $\begin{array}{l}-0.0986 \\
(0.0767)\end{array}$ & $\begin{array}{c}0.103 \\
(0.0845)\end{array}$ & $\begin{array}{r}-0.0389 \\
(0.0962)\end{array}$ & $\begin{array}{c}0.0284 \\
(0.0745)\end{array}$ & $\begin{array}{l}-0.0368 \\
(0.0635)\end{array}$ \\
\hline Post*HA & $\begin{array}{c}0.107^{*} \\
(0.0535)\end{array}$ & $\begin{array}{c}0.0681 \\
(0.0713)\end{array}$ & $\begin{array}{l}0.162^{* *} \\
(0.0682)\end{array}$ & $\begin{array}{c}0.0948 \\
(0.0962)\end{array}$ & $\begin{array}{c}0.203 * * * \\
(0.0675)\end{array}$ & $\begin{array}{c}0.0191 \\
(0.0627)\end{array}$ \\
\hline Post*BR & $\begin{array}{c}0.0493 \\
(0.0476)\end{array}$ & $\begin{array}{c}0.0494 \\
(0.0644)\end{array}$ & $\begin{array}{c}0.0355 \\
(0.0714)\end{array}$ & $\begin{array}{c}0.102 \\
(0.0938)\end{array}$ & $\begin{array}{c}0.0531 \\
(0.0669)\end{array}$ & $\begin{array}{c}0.0462 \\
(0.0504)\end{array}$ \\
\hline Constant & $\begin{array}{c}-1.433^{* * *} \\
(0.0498)\end{array}$ & $\begin{array}{c}-1.309 * * * \\
(0.0483)\end{array}$ & $\begin{array}{c}-1.477^{* * *} \\
(0.0579)\end{array}$ & $\begin{array}{c}-1.647^{* * *} \\
(0.0658)\end{array}$ & $\begin{array}{c}-1.395^{* * *} \\
(0.0690)\end{array}$ & $\begin{array}{r}-1.470^{* * *} \\
(0.0428)\end{array}$ \\
\hline $\begin{array}{l}\text { Observations } \\
\text { R-squared }\end{array}$ & $\begin{array}{l}9377 \\
0.014\end{array}$ & $\begin{array}{l}4164 \\
0.016\end{array}$ & $\begin{array}{r}3383 \\
0.014\end{array}$ & $\begin{array}{l}1720 \\
0.016\end{array}$ & $\begin{array}{l}4581 \\
0.013 \\
\end{array}$ & $\begin{array}{l}4796 \\
0.015 \\
\end{array}$ \\
\hline
\end{tabular}

\subsection{Theory}

Assume one risk neutral principal (the government) and $n$ risk averse agents (center workers), each responsible for producing output. In our scenario, the output could mean healthier (and less malnourished) children. Each agent exerts an effort and receives a wage from the principal. The agents' efforts are not visible to the principal, and therefore the principal can only contract based on the agents' output levels. For simplicity, we assume that the agents' effort levels are discrete, namely 0, 1, and 2. Agents produce two levels of outputs: 0 or 1 . The probability of attaining the high output depends on the agents' effort level: the higher the agent's effort, the higher her chance for producing 1 as opposed to 0 . Assume for simplicity that an effort of 0 produces an output 0 , an effort of 1 produces an output of 1 with probability $1 / 2$ and 0 with probability $1 / 2$, and an effort of 2 leads to an output of 1 .

We also assume a common shock in production. This could be thought of as a shock that causes output to shrink for all workers and is outside 
their control. In our setting, this could represent the onset of a disease (for example, malaria especially during the rainy season). With probability $\theta$, all the agents produce 0 regardless of their effort level. The agents' utility function is given as follows:

$$
U_{A}=V(w)-\frac{1}{2} c x^{2}
$$

Here, $w$ is the wage this agent receives, $c$ is the multiplier of the disutility caused by the agents' effort and $x$ is the agents' effort level. Agents are assumed to be risk averse, thus $V$ is an increasing and concave in $w$.

The principal's utility function is as follows:

$$
U_{p}=M \sum_{i=1}^{n} p_{i}-\sum_{i=1}^{n} w_{i}
$$

$p_{i}$ is the output level for agent $i, n$ is the number of the agents, $M$ is the multiplier for the agents' outputs. ${ }^{16}$ Moreover, it is always worthwhile for the principal to engage the agents in the highest level of effort $(x=2)$. Thus, the products are sufficiently valuable to the principal, i.e. $M$ is sufficiently large.

\subsection{Cost for an Absolute Performance Pay Scheme}

Suppose the wage for the agent is $a$ for output $=0$, and $b$ for output $=1$. Clearly $b>a$. The expected utility for agents with each of the different effort levels is:

$$
E\left(U_{A}(0)\right)=V(a)
$$

\footnotetext{
${ }^{16} M$ is assumed to be greater than one.
} 


$$
\begin{gathered}
E\left(U_{A}(1)\right)=\frac{1+\theta}{2} V(a)+\frac{1-\theta}{2} V(b)-\frac{1}{2} c \\
E\left(U_{A}(2)\right)=\theta V(a)+(1-\theta) V(b)-2 c
\end{gathered}
$$

To implement the highest effort level, the principal needs to make sure that the agent's utility with highest level of effort $(x=2)$ is the greatest in comparison to the other two effort levels. This boils down to the following condition: ${ }^{17}$

$$
V(b)-V(a)>\frac{3 c}{1-\theta}
$$

Thus, the difference between the utilities generated by the high wage and the low wage should be large enough. The principal could achieve this by lowering $a$. However, practically, there is a lower bound on $a$. If an agent produces 0 , the principal needs to make sure that the agent can survive on her wage. This condition is particularly relevant in the public sector, where workers are difficult to fire and where unionization resists cutting down on wages of unproductive workers. We can suppose that $V(a)>U$. It follows that $V(b)>\frac{3 c}{1-\theta}+U$. The total cost for the principal to implement a high effort for all agents under the absolute performance pay is as follows:

$$
C_{\text {absolute }}=n \times\left(\theta V^{-1}(U)+(1-\theta) V^{-1}\left(\frac{3 c}{1-\theta}+U\right)\right) .
$$

\subsection{Cost for a Relative Performance Pay Scheme}

When there are $n$ agents, a complete relative performance pay scheme should have $n+1$ contingencies, which boils down to $2 \times(n-1)+2=2 n$ number of payments. For example, in a three agents case, a complete tournament scheme would need to specify payments for output combinations $(1,1,1),(1$,

\footnotetext{
${ }^{17}$ See Appendix for details.
} 
$1,0),(1,0,0),(0,0,0)$, which contains six kinds of pay. Denoting the pay structure $\left(H_{0}, L_{0} ; H_{1}, L_{1} ; \ldots ; H_{n}, L_{n}\right), H$ corresponds to pay on high output, and $L$ corresponds to low output pay. The subscript $n$ on $L_{n}$ and $H_{n}$ corresponds to the number of agents who produce low output.

When all agents produce the same output - be it 1 or 0 - the relative rank for each agent is the same. For example, if there is a common shock, output will be low for all agents and all of them will receive $L_{n}$. On the other hand, if everyone exerts high effort and there is no common shock, the output will be high and all agents will receive $H_{0}$. As the rank structure is exactly the same in both cases, all workers should receive the same wage under a relative scheme: $H_{0}=L_{n}$.

We only need to compute the cost for the principal to make effort level portfolio $(2,2,2, \ldots, 2)$ a Nash Equilibrium. agent choose 0 or 1 over 2, provided everyone else chooses 2. From our previous assumptions,

$$
H_{0}=L_{n}=T
$$

Assuming that $(n-1)$ agents have already chosen effort level of 2, the expected utilities of the $n^{\text {th }}$ agent to choose $0,1,2$ are respectively:

$$
\begin{gathered}
E\left(U_{A}(0)\right)=\theta V(T)+(1-\theta) V\left(L_{1}\right) \\
E\left(U_{A}(1)\right)=\frac{1+\theta}{2} V(T)+\frac{1-\theta}{2} V\left(L_{1}\right)-\frac{1}{2} c \\
E\left(U_{A}(2)\right)=V(T)-2 c
\end{gathered}
$$

The inequality that arises out of solving the above problem along with the minimum utility assumption leads to $V(T) \geqslant U+3 c$. The minimized 
total cost for a principal using tournament is

$$
C_{\text {relative }}=n \times V^{-1}(U+3 c) \text {. }
$$

For more details see below:

In the absolute performance pay case:

$$
\begin{aligned}
E\left(U_{A}(2)\right)-E\left(U_{A}(0)\right) & =\theta V(a)+(1-\theta) V(b)-2 c-V(a) \\
& =(1-\theta)(V(b)-V(a))-2 c>0
\end{aligned}
$$

i.e.

$$
\begin{aligned}
& V(b)-V(a)>\frac{2 c}{1-\theta} \\
E\left(U_{A}(2)\right)-E\left(U_{A}(1)\right)= & \theta V(a)+(1-\theta) V(b)-2 c-\frac{1+\theta}{2} V(a)-\frac{1-\theta}{2} V(b)+\frac{1}{2} c \\
= & \frac{1-\theta}{2}(V(b)-V(a))-\frac{3}{2} c>0
\end{aligned}
$$

i.e.

$$
V(b)-V(a)>\frac{3 c}{1-\theta}
$$

Notice that this condition dominates the first one.

In the relative performance pay case:

To make 2 a best response, it is necessary that:

$$
\begin{aligned}
E\left(U_{A}(2)\right)-E\left(U_{A}(0)\right) & =V(T)-2 c-\theta V(T)-(1-\theta) V\left(L_{1}\right) \\
& =(1-\theta)\left(V(T)-V\left(L_{1}\right)\right)-2 c>0
\end{aligned}
$$


which implies that

$$
\begin{aligned}
V(T)-V\left(L_{1}\right)>\frac{2 c}{1-\theta} \\
E\left(U_{A}(2)\right)-E\left(U_{A}(1)\right)= \\
=\frac{1-\theta}{2}\left(V(T)-V\left(L_{1}\right)\right)-\frac{3}{2} c>0
\end{aligned}
$$

which implies that $V$

$$
(T)-V\left(L_{1}\right)>\frac{3 c}{1-\theta}(*)
$$

Notice this condition dominates the first one.

Similarly, we assume that in the worst case scenario, the agent should also attain the same minimum utility level $U$. This means that:

$$
\theta V(T)+(1-\theta) V\left(L_{1}\right) \geqslant U \quad(* *)
$$

The cost is minimized when $(* *)$ holds, i.e., when $V\left(L_{1}\right)=\frac{U-\theta V(T)}{1-\theta}$. Plug it in $(*)$, it follows that:

$$
V(T)-\frac{U-\theta V(T)}{1-\theta} \geqslant \frac{3 c}{1-\theta}
$$

which implies that

$$
(1-\theta) V(T)-U+\theta V(T) \geqslant 3 c
$$

$$
\begin{aligned}
C_{\text {absolute }}-C_{\text {relative }} & =n \times\left(\theta V^{-1}(U)+(1-\theta) V^{-1}\left(\frac{3 c}{1-\theta}+U\right)\right)-n \times V^{-1}(U+3 c) \\
& =n\left(\theta V^{-1}(U)+(1-\theta) V^{-1}\left(\frac{3 c}{1-\theta}+U\right)-V^{-1}(U+3 c)\right)
\end{aligned}
$$

Notice the difference is actually 0 when $\theta=0$. To see how this differ- 
ence varies with $\theta$, we take its derivative about $\theta$. For convenience, suppose $V^{-1}(x)=h(x)$. Since $V(x)$ is concave and increasing, its inverse function $h(x)$ is convex and increasing.

$$
\begin{aligned}
\left(C_{\text {absolute }}-C_{\text {relative }}\right)^{\prime} & =n\left(h(U)-h\left(\frac{3 c}{1-\theta}+U\right)+(1-\theta) h^{\prime}\left(\frac{3 c}{1-\theta}+U\right) \times \frac{3 c}{(1-\theta)^{2}}\right) \\
& =n\left(h(U)-h\left(\frac{3 c}{1-\theta}+U\right)+h^{\prime}\left(\frac{3 c}{1-\theta}+U\right) \times \frac{3 c}{(1-\theta)}\right)
\end{aligned}
$$

Since $h(x)$ is a continuous function on its domain, by Mean Value Theorem, it follows that

$$
h\left(\frac{3 c}{1-\theta}+U\right)-h(U)=\left(\frac{3 c}{1-\theta}+U-U\right) h^{\prime}\left(U^{*}\right)=\frac{3 c}{1-\theta} h^{\prime}\left(U^{*}\right)
$$

where

$$
U^{*} \in\left(U, \frac{3 c}{1-\theta}+U\right)
$$

Plug it back in:

$$
\begin{aligned}
\left(C_{\text {absolute }}-C_{\text {relative }}\right)^{\prime} & =h^{\prime}\left(\frac{3 c}{1-\theta}+U\right) \times \frac{3 c}{(1-\theta)}-\frac{3 c}{1-\theta} h^{\prime}\left(U^{*}\right) \\
& =\frac{3 c}{1-\theta}\left(h^{\prime}\left(\frac{3 c}{1-\theta}+U\right)-h^{\prime}\left(U^{*}\right)\right)
\end{aligned}
$$

Notice that

$$
\frac{3 c}{1-\theta}+U>U^{*}
$$

Since $h(x)$ is convex, it follows that

$$
h^{\prime}\left(\frac{3 c}{1-\theta}+U\right)>h^{\prime}\left(U^{*}\right)
$$




\subsection{Comparison between absolute and relative schemes}

As shown in the previous section:

$$
C_{\text {absolute }}>C_{\text {relative }} \text { for } \theta>0 \text {. }
$$

The cost for an absolute scheme is higher than that for a relative scheme whenever common shock is possible. This result is in contrast to the stylized one in the current literature, which states that the absolute scheme should dominate the relative schemes when the probability of common shock is low enough or when it is not present (Green and Stokey, 1983). The "public sector assumption" that assumes that agents should obtain a minimum level of utility even when they perform poorly leads to the principal optimally choosing a more cost effective relative scheme for extracting high effort from its agents. Additionally, a practical advantage of the relative scheme for a risk averse policy maker is that he is certain of the cost ex-ante. 